\title{
A Full-Scale Comparative Study of Conventional and Side-Stream Enhanced Biological Phosphorus Removal Processes
}

\author{
Dongqi Wang ${ }^{1,2}$, Nicholas B. Tooker ${ }^{2}$, Varun Srinivasan ${ }^{2}$, Guangyu $\mathrm{Li}^{2}$, Peter Schauer ${ }^{3}$, Adrienne \\ Menniti $^{3}$, Chris Maher ${ }^{3}$, Charles B. Bott ${ }^{4}$, Paul Dombrowski ${ }^{5}$, James L. Barnard ${ }^{6}$, Annalisa \\ Onnis-Hayden ${ }^{2}$ and April Z. Gu ${ }^{2,7, *}$ \\ ${ }^{1}$ State Key Laboratory of Eco-hydraulics in Northwest Arid Region, Xi'an University of \\ Technology, Xi'an, Shaanxi 710048, China \\ ${ }^{2}$ Department of Civil and Environmental Engineering, Northeastern University, 360 Huntington \\ Avenue, Boston, MA 02115, United States \\ ${ }^{3}$ Clean Water Services, 16060 SW 85th Avenue, Tigard, OR 97224, United States \\ ${ }^{4}$ Hampton Roads Sanitation District, 1434 Air Rail Avenue, Virginia Beach, VA 23454, United \\ States \\ ${ }^{5}$ Woodard \& Curran, Inc., 1699 King Street, Enfield, CT 06082, United States \\ ${ }^{6}$ Black \& Veatch, 8400 Ward Parkway, Kansas City, MO 64114, United States \\ ${ }^{7}$ School of Civil and Environmental Engineering, Cornell University, 220 Hollister Hall, Ithaca, \\ NY 14853, United States
}

\begin{abstract}
:
In this study, a full-scale pilot testing was performed with side-by-side operation of a conventional enhanced biological phosphorus removal (EBPR) process and a side-stream EBPR (S2EBPR) process. A comparison of the performance, activities and population dynamics of key functionally relevant populations between the two configurations were carried out. The results demonstrated that, with the same influent wastewater characteristics, S2EBPR configuration showed more effective and stable orthophosphate $\left(\mathrm{PO}_{4}-\mathrm{P}\right)$ removal performance (up to $94 \%$ with average effluent concentration down to $0.1 \mathrm{mg}$ P/L) than conventional EBPR, especially when the mixers in side-stream reactor were operated intermittently. Mass balance analysis illustrated that both denitrification and EBPR performance have been enhanced in S2EBPR configuration through diverting primary effluent to anoxic zone and producing additional carbon ( 40\%) via fermentation in side-stream reactor. Microbial characterization showed that there was no significant difference in the relative abundances of Accumulibacter $(\sim 5.9 \%)$ and Tetrasphaera $(\sim 16 \%)$ putative polyphosphate-accumulating organisms (PAOs) between the two configurations. However, lower relative abundance of known GAOs was observed in S2EBPR configuration $(1.1 \%)$ than the conventional one $(2.7 \%)$. A relatively higher PAO activity and increased degree of dependence on glycolysis pathway than TCA cycle was observed in S2EBPR configuration using P release and uptake batch test. Adequate anaerobic solid retention time (SRT) and conditions that generate continuous and slow feeding/production of volatile fatty acid (VFA) with higher composition percentage of propionate in the side-stream reactor of S2EBPR process likely provide a competitive advantage for PAOs over GAOs.
\end{abstract}

Keywords: EBPR; side-stream; performance comparison; microbial ecology; activity

* Corresponding author.

E-mail address: aprilgu@cornell.edu (A. Z. Gu) 


\section{Introduction}

The anthropogenic discharge of phosphorus $(\mathrm{P})$ needs to be managed as it will cause undesirable eutrophication and water quality deterioration in receiving waters (Cordell et al., 2009; Rittmann et al., 2011). The enhanced biological phosphorus removal (EBPR) process, which enriches and utilizes a group of polyphosphate-accumulating organisms (PAOs) to take up inorganic phosphorus from wastewater by intracellular accumulation, has been demonstrated as a promising method for removal of phosphorus with economic and environmental benefits compared to chemical phosphorus removal (Oehmen et al., 2007). Challenges remain for the EBPR-employed water resource recovery facilities (WRRFs) in complying with more and more stringent effluent $P$ limits due to inconsistent process performance, which is often a result of inadequate or variable influent readily degradable carbon (rbCOD) (Barnard and Abraham, 2006; Gu et al., 2008; Neethling et al., 2005). As an alternative to conventional EBPR, the side-stream EBPR (S2EBPR) process adds a side-stream anaerobic reactor where a portion or all of the return activated sludge (RAS) or mixed liquor suspended solids (MLSS) undergoes hydrolysis and fermentation, and the overflow from this reactor is directed back to the main-stream biological process. Compared to the conventional mainstream EBPR, S2EBPR process requires fewer chemicals, smaller footprint, produces fewer odors, provides additional carbon for denitrification, and can be implemented in a variety of existing EBPR configurations without reliance on influent carbon (Barnard et al., 2016; Tooker et al., 2017).

Currently, over 80 full-scale facilities and numerous pilot studies throughout the world have implemented S2EBPR, and 13 of which are in the United States. However, the development of S2EBPR process is still in its infancy in many countries around the world, requiring more fullscale demonstrations to promote its applications. Even though there were several case studies (Andreasen et al., 1997; Petersen, 2002; Vollertsen et al., 2006; Copp et al., 2012) showing effective and stable EBPR performance in the S2EBPR process, a performance comparison among them is difficult to interpret due to differences in influent wastewater characteristics, process design, and other plant-specific factors. Competition between the two EBPR-relevant functional populations, PAOs and glycogen-accumulating organisms (GAOs), has been considered critical for a successful EBPR process. By applying molecular methods such as fluorescence in situ hybridization (FISH), qPCR and 16S rRNA gene amplicon sequencing, the identity, biodiversity, and ecology of EBPR-relevant functional populations have been extensively studied (Crocetti et al., 2002; Kong et al., 2005; Oehmen et al., 2007; He et al., 2011; Nguyen et al., 2011; McIlroy et al., 2014; Coats et al., 2017; Stokholm-Bjerregaard et al. 2017). However, very limited number of microbiological studies have been focused on the S2EBPR process and its comparison with conventional process (Lanham et al., 2013a; Mielczarek et al. 2013; Stokholm-Bjerregaard et al. 2015). The high variations in wastewater components, operations and environment among different WRRFs also make it challenging for full-scale studies to reveal differences in microbial ecology between S2EBPR and conventional EBPR, which are essential for elucidating the fundamental mechanisms. Additionally, there is also a lack of standard design and operating guidance for the S2EBPR process, including proportion of RAS diversion, solid retention time (SRT) and hydraulic retention time (HRT) in side-stream reactor, mixing conditions, and key parameters for process monitoring.

To demonstrate and evaluate differences in performance between S2EBPR and conventional EBPR configurations and investigate the underlying mechanisms involved in S2EBPR process, a full-scale pilot testing with side-by-side parallel operation of two independent treatment trains was performed at the Rock Creek Advanced Wastewater Treatment Facility (Clean Water Services, Hillsboro, United States). In addition to routine influent and effluent water quality monitoring, carbon, nitrogen, and phosphorus mass balances, in situ and ex situ EBPR activity and kinetics tests, and microbial ecology analyses (including FISH, 4',6-diamidino-2- 
phenylindole (DAPI) staining and 16S rRNA gene amplicon sequencing) were simultaneously conducted in each process. The impacts of different operational parameters and environmental factors on removal performance were evaluated to better understand and optimize the S2EBPR process. To the best of our knowledge, this is a first comprehensive, side-by-side investigation of full-scale S2EBPR and conventional EBPR configurations that receiving the same influent wastewater. This research will improve understanding of S2EBPR processes, the associated microbial community structure and phenotypes, and the principal factors that govern process optimization.

\section{Material and methods}

\subsection{Facility description and pilot testing}

Full-scale pilot testing was conducted during summer and fall of 2016 in two parallel treatment trains at the Rock Creek Facility. Treatment is accomplished by primary treatment, activated sludge biological nutrient removal (BNR, see key process parameters in Table S1), tertiary phosphorus removal, including filtration, and disinfection. Primary sludge is processed through a unified fermentation and thickening (UFAT) process, and the volatile fatty acid (VFA)rich supernatant is directed to the RAS lines of the biological treatment process to improve EBPR and denitrification. Two biological treatment trains, aeration basins 4 and 5 (referred to as AB4 and AB5), were selected for the pilot testing due to their operational independence and piping flexibility of the UFAT supernatant, primary effluent (PE), and RAS lines.

Prior to beginning pilot testing, AB4 and AB5 were operated in the same configuration (A/O), and the RAS from the two treatment trains was blended together. When pilot testing commenced, the RAS from AB4 and AB5 were split, and the two treatment trains were operated independently. During Phase I-A, AB4 was operated in a conventional A2O configuration as a control. AB5 was operated in a side-stream RAS with supplemental carbon (SSRC) configuration (Figure 1) with primary effluent entering the anoxic zone (Cells 3 and 4). The anaerobic zone (Cells 1 and 2) was operated as the side-stream reactor. The anaerobic side-stream reactor in the S2EBPR (SSRC) configuration was continuously mixed during Phase I-A. During Phase I-B the mixers in the side-stream anaerobic reactor for S2EBPR configuration were switched from continuous to intermittent operation. During this phase, the mixers in the anaerobic side-stream reactor for S2EBPR configuration were cycled on once per week for approximately 10 minutes. All other operating parameters for both A2O and S2EBPR configurations were the same as in Phase I-A. A summary of the specific operational conditions for each treatment train during the pilot testing is shown in Table 1. P release-uptake batch testing was performed to evaluate EBPR activities, FISH and DAPI microscopy were used to quantify specific functionally-relevant microorganisms. Chemical analyses, including volatile fatty acids (VFAs), nutrients, total suspended solids (TSS), volatile suspended solids (VSS), chemical oxygen demand (COD), soluble COD (sCOD) and alkalinity were performed to assess system performance. The sampling sites, frequency, and dates are shown in Table S2.

(a)

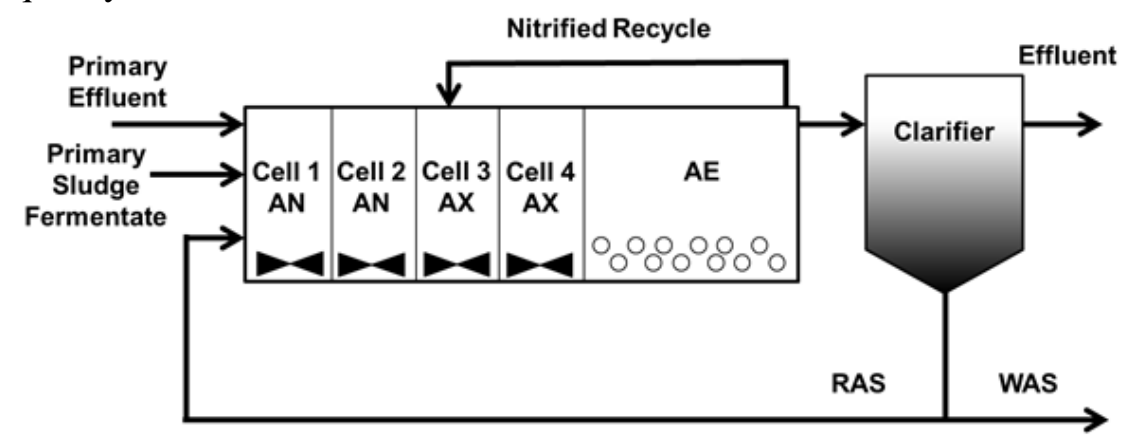


(b)

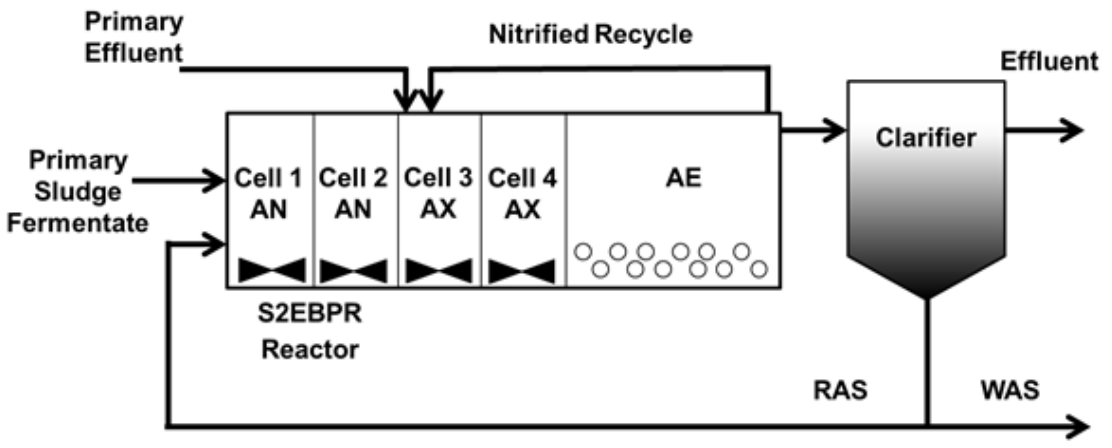

Figure 1 Schematic flow diagrams of two parallel treatment trains at Rock Creek Facility (Hillsboro, USA) with (a) A2O configuration and (b) SSRC (side-stream RAS fermentation with supplemental carbon addition) configuration.

Table 1 Phases and operational conditions of full-scale pilot testing for performance comparison between conventional A2O and S2EBPR (SSRC) configuration at Rock Creek Facility (Hillsboro, USA).

\begin{tabular}{|c|c|c|c|c|}
\hline \multirow{2}{*}{ Parameter } & \multicolumn{2}{|c|}{ Phase I-A } & \multicolumn{2}{|c|}{ Phase I-B } \\
\hline & $\mathrm{AB} 4$ & AB5 & $\mathrm{AB} 4$ & AB5 \\
\hline Period & \multicolumn{2}{|c|}{ April 26-June 21, 2016} & \multicolumn{2}{|c|}{ June 22-August 31, 2016} \\
\hline Configuration & $\mathrm{A} 2 \mathrm{O}$ & S2EBPR (SSRC) & $\mathrm{A} 2 \mathrm{O}$ & S2EBPR (SSRC) \\
\hline $\begin{array}{l}\text { Mixing condition in } \\
\text { anaerobic zone }\end{array}$ & $\begin{array}{l}\text { Continuous } \\
\text { mixing }\end{array}$ & $\begin{array}{l}\text { Continuous } \\
\text { mixing }\end{array}$ & $\begin{array}{l}\text { Continuous } \\
\text { mixing }\end{array}$ & $\begin{array}{l}\text { Intermittent } \\
\text { mixing }^{\mathrm{a}}\end{array}$ \\
\hline $\begin{array}{c}\text { Anaerobic HRT } \\
\text { (h) }\end{array}$ & 0.6 & 1.6 & 0.8 & 2.1 \\
\hline $\begin{array}{c}\text { RAS diversion } \\
(\%)\end{array}$ & 100 & 100 & 100 & 100 \\
\hline $\begin{array}{c}\text { RAS rate } \\
(\% \mathrm{Q})\end{array}$ & 40 & 40 & 35 & 35 \\
\hline $\begin{array}{c}\text { MLSS in RAS } \\
(\mathrm{g} / \mathrm{L})\end{array}$ & 11.3 & 11.9 & 10.1 & 9.8 \\
\hline $\begin{array}{c}\text { MLSS in } \\
\text { mainstream } \\
(\mathrm{g} / \mathrm{L})\end{array}$ & 3.3 & 3.6 & 2.7 & 2.7 \\
\hline
\end{tabular}

a: mixers were operated once per week for $10 \mathrm{mins} ;{ }^{\mathrm{b}}$ : calculated based on primary effluent flow rate.

\subsection{Phosphorus release and uptake batch testing}

To evaluate the EBPR activity of the activated sludge collected from Rock Creek Facility during the pilot testing, $\mathrm{P}$ release and uptake kinetics tests were conducted in accordance with previously described protocols (Gu et al., 2008). Briefly, samples were initially aerated for $1 \mathrm{~h}$ to remove residual organics, and then nitrogen gas was sparged into the sample to obtain anaerobic conditions (defined by a dissolved oxygen concentration of less than $0.1 \mathrm{mg} / \mathrm{L}$ ), sodium acetate was added to achieve an initial reactor concentration of $\sim 80 \mathrm{mg} \mathrm{Ac/L}$, and sparging with nitrogen gas continued for $45 \mathrm{~min}$. After completion of the anaerobic phase, air was bubbled in to the reactor to obtain aerobic conditions for $3 \mathrm{~h}$. Samples were collected periodically throughout the entire testing period to analyse VFA, orthophosphate $\left(\mathrm{PO}_{4}-\mathrm{P}\right)$, poly- $\beta$-hydroxyalkanoates (PHAs), glycogen, and VSS. The reactor $\mathrm{pH}$ was continuously monitored and adjusted to maintain the $\mathrm{pH}$ between 6.9 and 7.1 by addition of $\mathrm{NaOH}$ or $\mathrm{HCl}$. Temperature was maintained at $20 \pm 1{ }^{\circ} \mathrm{C}$ throughout the test. 


\subsection{Microbial characterisation}

Quantitative FISH was used for quantification of specific functionally relevant microorganisms, including known PAOs (Accumulibacter and Tetrasphaera) and known GAOs (Defluvicoccus, Competibacter, and Propionivibrio). The fraction of these organisms present was quantified as a proportion of the total viable cells using a mix of general bacterial probes (EUB mix). The FISH protocol and hybridization conditions that were used have been described previously (He et al., 2008; Onnis-Hayden et al., 2011; Zilles et al., 2002). A summary of the FISH probes utilized is included in Table S3. Quantification of population distributions for FISH images was carried out using the DAIME software (Daims et al., 2006). A minimum of 20 random images were analyzed for each sample, and the average biovolume reported. The differential staining of PAOs and non-PAOs was performed with DAPI at $50 \mu \mathrm{g} / \mathrm{mL}$ for $1 \mathrm{~min}$ (Kawaharasaki et al., 1999). The polyP-DAPI complex fluoresces bright yellow against the blue fluorescent background of the DNA-DAPI complex. The biovolume of total PAOs (yellow) was estimated as the percentage of the total cells (blue) using the DAIME software (Daims et al., 2006). Sampling for 16s rRNA gene amplicon sequencing was performed at the end of the aerobic zone in each configuration during the pilot testing. Genomic DNA was extracted from activated sludge samples using the Fast-DNA Spin kit for Soil (MP Biomedicals, Vista, CA, USA). The extracted DNA was sent to University of Connecticut-MARS facility for PCR amplification and sequencing targeting the $\mathrm{V} 4$ region using the primers $515 \mathrm{~F}\left(5^{\prime}-\right.$

GTGCCAGCMGCCGCGGTAA-3') and 806R (5'-GGACTACHVGGGTWTCTAAT-3') and the amplicons were sequenced on the Illumina MiSeq using V2 chemistry using paired-end $(2 \times 250)$ sequencing. The raw Fastq files were cleaned using Sickle 1.33 with a minimum window quality score of 20 . The sequences were trimmed to remove primers and barcodes, quality filtered using sickle v1.33 with a minimum quality score of 20 and analyzed as described previously (Kozich et al., 2013). Consensus taxonomy of OTUs was determined using the $80 \%$ cutoff using the MiDAS (v123) database. Amplicon data was rarefied to the minimum total sequence count (12090 sequences) across all samples. All data and statistical analysis were performed in R using the following packages: vegan, ggplot2, dplyr and ampvis (Albertsen et al., 2015).

\subsection{Chemical analyses}

VFAs, including acetic, propionic, n-butyric, isobutyric, n-valeric, and isovaleric acids were analyzed using high performance liquid chromatography (HPLC) in accordance with previously described methods (Carvalho et al., 2007). COD, TSS and VSS, and nutrients, including total phosphorus (TP), $\mathrm{PO}_{4}-\mathrm{P}$, total nitrogen $(\mathrm{TN})$, nitrate $\left(\mathrm{NO}_{3}-\mathrm{N}\right)$, nitrite $\left(\mathrm{NO}_{2}-\mathrm{N}\right)$, and ammonia $\left(\mathrm{NH}_{4}-\mathrm{N}\right)$, were analyzed in accordance with Standard Methods (APHA 2013). PHAs were extracted from freeze-dried sludge samples in accordance with previously described methods using a $3 \mathrm{~h}$ digestion time and a 3\% sulfuric acid concentration, and analyzed using gas chromatography-mass spectrometry (GC-MS) (Lanham et al., 2013b). Glycogen was extracted from freeze-dried sludge samples in accordance with previously described methods with a $2 \mathrm{~h}$ digestion time and 0.9 M hydrochloric acid (Lanham et al., 2012), and analyzed using liquid chromatography-tandem mass spectrometry (LC-MS/MS). The LC-MS/MS analysis was performed on a Prominence UFLC (Shimadzu, Kyoto, Japan) and an AB Sciex Qtrap® 4500 MS/MS (AB Sciex, Framingham, MA, USA) using an Aminex ${ }^{\circledR}$ HPX-87H column $(300 \times 7.8$ $\mathrm{mm}, 9 \mu \mathrm{m})$ (Bio-Rad Laboratories, Hercules, CA, USA). ${ }^{13} \mathrm{C}_{6}$-glucose (Cambridge Isotope Laboratories, Inc., Andover, MA, USA) was used as the surrogate standard for quantification. 


\section{Results}

\subsection{Influent characterization and treatment efficiency}

Concentrations of COD, TSS, TN, $\mathrm{NH}_{4}-\mathrm{N}$, TP and $\mathrm{PO}_{4}-\mathrm{P}$ in PE and SE, and removal efficiencies in both A2O and S2EBPR configurations during the pilot testing are shown in Table 2 . The average COD, TSS, and TN removals ( $\sim 89 \%, \sim 92 \%$, and $\sim 61 \%$, respectively) were relatively similar between the two configurations, and the average SE concentrations were only slightly different during the pilot testing. The average $\mathrm{SE} \mathrm{NH}_{4}-\mathrm{N}$ concentration in both configurations was below $1.2 \mathrm{mg} / \mathrm{L}$ during Phase I-A, and it was less than $0.3 \mathrm{mg} / \mathrm{L}$ during Phase I-B. The average SE TP concentration in both A2O and S2EBPR configurations was below 1.0 $\mathrm{mg} / \mathrm{L}$, with a TP removal efficiency of greater than $80 \%$. In A2O configuration, the average SE TP concentration and removal efficiency remained the same throughout Phase I. In S2EBPR configuration, the average SE TP concentration decreased to $0.3 \mathrm{mg} / \mathrm{L}$ during Phase I-B, indicating effective EBPR performance with a TP removal efficiency of $93 \%$.

Table 2 Characterization of primary effluent, secondary effluent, and removal efficiencies of A2O and S2EBPR configurations during each phase of full-scale pilot testing (average \pm standard deviation; in $\mathrm{mg} / \mathrm{L}$

\begin{tabular}{|c|c|c|c|c|}
\hline \multirow[b]{2}{*}{ Parameter } & \multicolumn{2}{|c|}{ Phase I-A } & \multicolumn{2}{|c|}{ Phase I-B } \\
\hline & $\mathrm{A} 2 \mathrm{O}$ & $\begin{array}{c}\text { S2EBPR } \\
\text { (continuous } \\
\text { mixing) } \\
\end{array}$ & $\mathrm{A} 2 \mathrm{O}$ & $\begin{array}{c}\text { S2EBPR } \\
\text { (intermittent } \\
\text { mixing) }\end{array}$ \\
\hline $\mathrm{COD}_{\text {in }}$ & \multicolumn{2}{|c|}{$254 \pm 39$} & \multicolumn{2}{|c|}{$292 \pm 33$} \\
\hline $\mathrm{COD}_{\text {out }}$ & $32 \pm 3$ & $28 \pm 2$ & $29 \pm 4$ & $28 \pm 2$ \\
\hline COD removal & $87 \%$ & $88 \%$ & $89 \%$ & $90 \%$ \\
\hline $\mathrm{TSS}_{\mathrm{in}}$ & \multicolumn{2}{|c|}{$68 \pm 14$} & \multicolumn{2}{|c|}{$80 \pm 28$} \\
\hline $\mathrm{TSS}_{\text {out }}$ & $9 \pm 3$ & $6 \pm 1$ & $5 \pm 1$ & $4 \pm 1$ \\
\hline TSS removal & $85 \%$ & $91 \%$ & $94 \%$ & $95 \%$ \\
\hline $\mathrm{TN}_{\mathrm{in}}$ & \multicolumn{2}{|c|}{$41 \pm 3$} & \multicolumn{2}{|c|}{$45 \pm 4$} \\
\hline $\mathrm{TN}_{\text {out }}$ & $17 \pm 2$ & $18 \pm 2$ & $18 \pm 2$ & $18 \pm 2$ \\
\hline TN removal & $60 \%$ & $57 \%$ & $62 \%$ & $63 \%$ \\
\hline $\mathrm{NH}_{4}-\mathrm{N}_{\mathrm{in}}$ & \multicolumn{2}{|c|}{$30 \pm 4$} & \multicolumn{2}{|c|}{$31 \pm 3$} \\
\hline $\mathrm{NH}_{4}-\mathrm{N}_{\text {out }}$ & $1.2 \pm 1.8$ & $0.8 \pm 1.2$ & $0.2 \pm 0.4$ & $0.3 \pm 0.3$ \\
\hline $\mathrm{NH}_{4}-\mathrm{N}$ removal & $96 \%$ & $97 \%$ & $99 \%$ & $99 \%$ \\
\hline $\mathrm{TP}_{\text {in }}$ & \multicolumn{2}{|c|}{$3.7 \pm 0.5$} & \multicolumn{2}{|c|}{$3.8 \pm 0.3$} \\
\hline $\mathrm{TP}_{\text {out }}$ & $0.7 \pm 0.4$ & $0.6 \pm 0.4$ & $0.7 \pm 0.4$ & $0.3 \pm 0.1$ \\
\hline TP removal & $82 \%$ & $84 \%$ & $82 \%$ & $93 \%$ \\
\hline $\mathrm{PO}_{4}-\mathrm{P}_{\text {in }}$ & \multicolumn{2}{|c|}{$1.7 \pm 0.8$} & \multicolumn{2}{|c|}{$2.1 \pm 0.5$} \\
\hline $\mathrm{PO}_{4}-\mathrm{P}_{\text {out }}$ & $0.6 \pm 0.9$ & $0.6 \pm 1.0$ & $0.4 \pm 0.3$ & $0.1 \pm 0.1$ \\
\hline $\mathrm{PO}_{4}-\mathrm{P}$ removal & $61 \%$ & $67 \%$ & $80 \%$ & $94 \%$ \\
\hline
\end{tabular}

in: primary effluent; out: secondary effluent

\subsection{Performance stability comparison}

Summary statistics and cumulative frequency analyses were conducted based on the daily operating data to better compare differences in EBPR performance and stability between A2O and S2EBPR configurations (Table S4, Figure 2, and Figure 3). During Phase I-A, there was no significant difference in performance between A2O and S2EBPR configurations. The median SE 
$\mathrm{PO}_{4}-\mathrm{P}$ concentration of $\mathrm{A} 2 \mathrm{O}$ and S2EBPR configurations were $0.24 \mathrm{mg} / \mathrm{L}$ and $0.17 \mathrm{mg} / \mathrm{L}$, respectively. During Phase I-B testing, the anaerobic side-stream reactor mixers in S2EBPR configuration were changed to intermittent operation, but no changes were made to the operation of A2O configuration. The performance in both treatment trains improved during this phase of testing, and the improvement was especially apparent in S2EBPR configuration. The median SE $\mathrm{PO}_{4}-\mathrm{P}$ concentration in S2EBPR configuration was $0.07 \mathrm{mg} / \mathrm{L}$, with a $\mathrm{PO}_{4}-\mathrm{P}$ removal efficiency up to $94 \%$, while the median $\mathrm{SE} \mathrm{PO}_{4}-\mathrm{P}$ concentration in A2O configuration was $0.36 \mathrm{mg} / \mathrm{L}$ during the same period. Additionally, during this phase of testing, the S2EBPR configuration achieved a SE $\mathrm{PO}_{4}-\mathrm{P}$ concentration of $0.1 \mathrm{mg} / \mathrm{L}$ or lower in $71 \%$ of the samples collected. During the same period, A2O configuration was only able to achieve a SE $\mathrm{PO}_{4}-\mathrm{P}$ concentration of 0.1 $\mathrm{mg} / \mathrm{L}$ or lower in $23 \%$ of the samples collected. This indicates that the S2EBPR configuration provided more stable and reliable EBPR performance compared to the conventional EBPR configuration. In addition, there were two large storm events (Figure 2) which caused a loss of EBPR performance in both of the treatment trains. However, the data seems to indicate a faster recovery in the S2EBPR system compared to the conventional system. The performance of the S2EBPR treatment train was then stable until a subsequent process upset related to another high flow event.

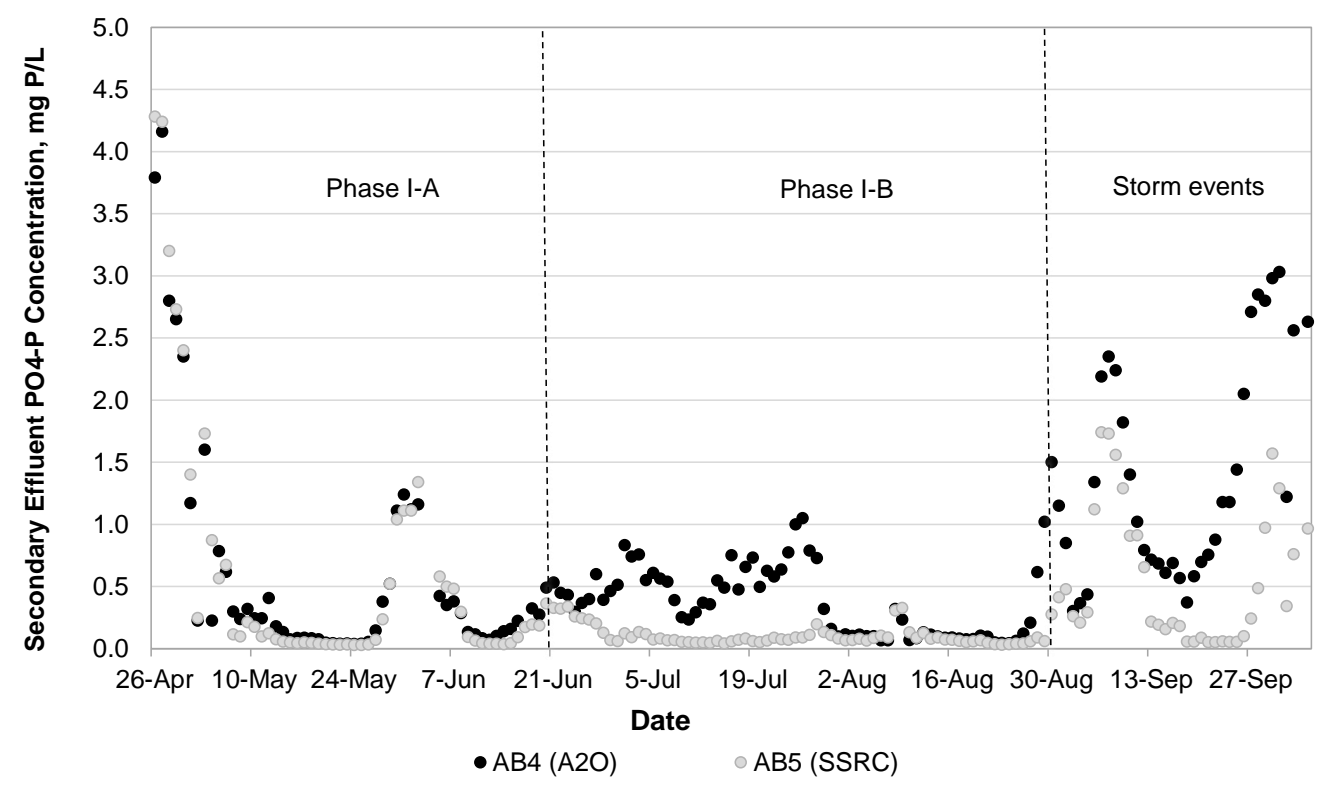

Figure 2 Comparison of secondary effluent $\mathrm{PO}_{4}-\mathrm{P}$ concentration between $\mathrm{A} 2 \mathrm{O}$ and S2EBPR configuration during full-scale pilot testing. 

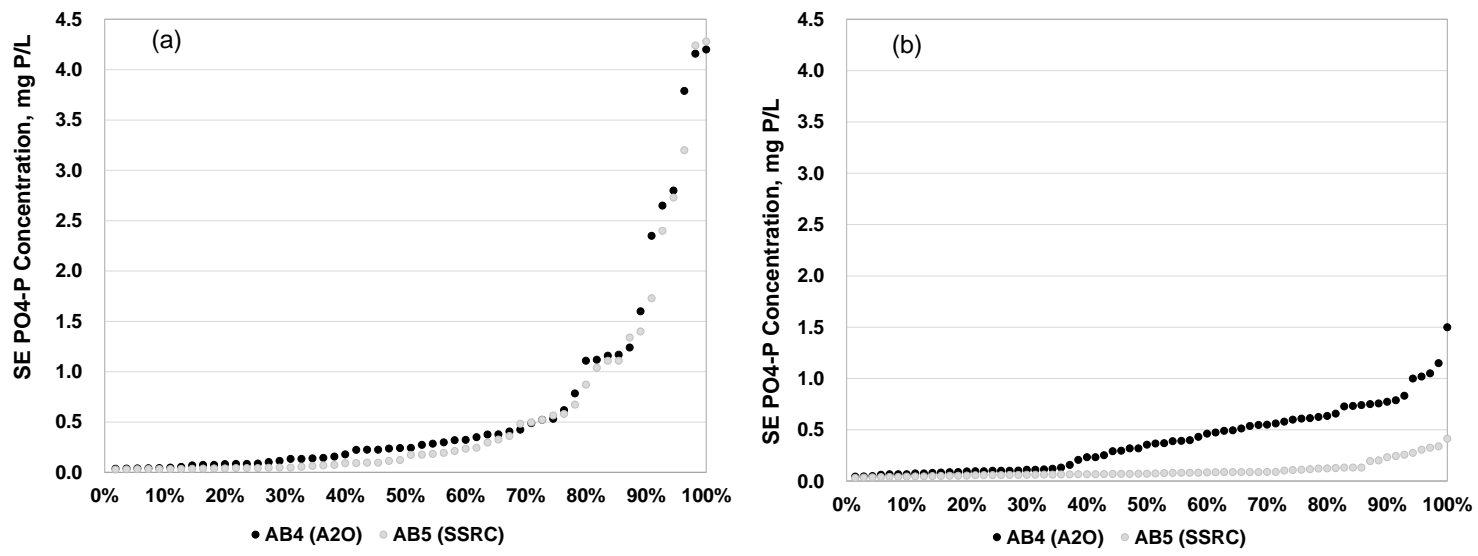

Figure 3 Cumulative frequency plot for secondary effluent $\mathrm{PO}_{4}-\mathrm{P}$ concentration in $\mathrm{A} 2 \mathrm{O}$ and S2EBPR configurations during (a) Phase I-A and (b) Phase I-B.

\subsection{Mass balances}

\subsubsection{Fate of carbon}

A COD mass balance for both configurations was conducted for data collected during Phase I-B (Table 3). The average input COD load, which included COD from PE ( $5430 \mathrm{~kg} \mathrm{COD} / \mathrm{d})$ and UFAT ( 410 kg COD/d), were similar for both A2O and S2EBPR configuration. The average effluent COD load was $582 \mathrm{~kg} \mathrm{COD} / \mathrm{d}$ for A2O configuration and $560 \mathrm{~kg} \mathrm{COD} / \mathrm{d}$ for S2EBPR configuration, both yielding a removal efficiency of $90 \%$. Nutrient requirements for biomass growth were calculated based on WAS and using previously defined stoichiometry (Grady et al., 1999; Henze et al., 2008, 2001). After subtracting P required for biomass growth, the P uptake for EBPR was estimated to be $128 \mathrm{~kg}$ P/d for A2O configuration and $160 \mathrm{~kg} \mathrm{P} / \mathrm{d}$ for S2EBPR configuration (based on the $\mathrm{P}$ uptake calculated in Section 3.3.3). The COD consumed for EBPR was therefore estimated to be $638 \mathrm{~kg} \mathrm{COD} / \mathrm{d}$ for A2O configuration and $798 \mathrm{~kg}$ COD/d for S2EBPR configuration.

Table 3 COD distributions and mass balance for A2O and S2EBPR configurations during Phase I-B.

\begin{tabular}{|c|c|c|c|c|}
\hline Component & $\begin{array}{c}\text { Load } \\
(\mathrm{kg} \\
\text { COD/d })\end{array}$ & $\begin{array}{l}\text { Normalized } \\
\text { concentration } \\
(\mathrm{mg} \text { COD/L) }\end{array}$ & $\begin{array}{l}\text { Distribution } \\
\quad(\%)\end{array}$ & Remarks \\
\hline \multicolumn{5}{|l|}{$\mathrm{A} 2 \mathrm{O}$} \\
\hline Input COD & 5852 & 291 & 100 & $\begin{array}{l}\text { PE flow: } 19871 \mathrm{~m}^{3} / \mathrm{d} \\
\text { UFAT flow: } 292 \mathrm{~m}^{3} / \mathrm{d}\end{array}$ \\
\hline Effluent COD & 582 & 29 & 10 & SE flow: $19870 \mathrm{~m}^{3} / \mathrm{d}$ \\
\hline $\begin{array}{l}\text { Wasting COD } \\
\text { (assimilation) }\end{array}$ & 3953 & 196 & 68 & $\begin{array}{c}\text { Waste sludge: } 315 \mathrm{~m}^{3} / \mathrm{d} \text {; } \\
\text { RAS/WAS VSS: } 8.9 \\
\text { kg/m } \mathrm{m}^{3}\end{array}$ \\
\hline $\begin{array}{l}\text { Heterotrophic } \\
\text { COD } \\
\text { utilization }\end{array}$ & 1317 & $\begin{array}{c}66 \\
\text { (32 for EBPR, } 23 \text { for } \\
\text { OHOs and } 11 \text { for } \\
\text { DN) }\end{array}$ & $\begin{array}{c}22 \\
\text { (11 for EBPR, } 7 \text { for } \\
\text { OHOs and } 4 \text { for DN) }\end{array}$ & \\
\hline \multicolumn{5}{|l|}{ S2EBPR } \\
\hline Input COD & 5839 & 291 & 100 & $\begin{array}{l}\text { PE flow: } 19871 \mathrm{~m}^{3} / \mathrm{d} \\
\text { UFAT flow: } 292 \mathrm{~m}^{3} / \mathrm{d}\end{array}$ \\
\hline Effluent COD & 560 & 28 & 10 & SE flow: $19802 \mathrm{~m}^{3} / \mathrm{d}$ \\
\hline $\begin{array}{l}\text { Wasting COD } \\
\text { (assimilation) }\end{array}$ & 3901 & 194 & 67 & Waste sludge: $314 \mathrm{~m}^{3} / \mathrm{d}$ \\
\hline
\end{tabular}




\begin{tabular}{ccc}
\hline & & RAS/WAS VSS: 8.8 \\
$\mathrm{kg} / \mathrm{m}^{3}$
\end{tabular}

Parameter values for calculation: COD-to-VSS ratio of biomass: $1.42 \mathrm{~g} \mathrm{COD/g} \mathrm{VSS;} \mathrm{N}$ and P requirements for biomass growth: $0.10 \mathrm{~g} \mathrm{~N} / \mathrm{g}$ VSS and $0.03 \mathrm{~g}$ P/g VSS (Ekama and Wentzel 2008); COD consumption for nitrate denitrification: $2.86 \mathrm{~g} \mathrm{COD} / \mathrm{g} \mathrm{NO}_{3}-\mathrm{N}$; VFA requirement for P removal: $10 \mathrm{~g} \mathrm{COD}_{\mathrm{VFA}} / \mathrm{g} \mathrm{P}_{\text {removed }}$ (Grady et al., 1999); observed yield coefficient $\left(Y_{o b s}\right): 0.5 \mathrm{~g} \mathrm{COD}_{\text {biomass }} / \mathrm{g} \mathrm{COD}_{\text {substrate }}$ (Henze et al. 1997); OHOs: ordinary heterotrophic organism; DN: denitrification.

The COD used for denitrification was estimated to be $208 \mathrm{~kg} \mathrm{COD} / \mathrm{d}$ for A2O configuration and $515 \mathrm{~kg} \mathrm{COD} / \mathrm{d}$ for S2EBPR configuration (based on the denitrified $\mathrm{NO}_{3}-\mathrm{N}$ calculated in Section 3.3.2). This indicates that the SSRC configuration benefitted not only PAOs but also denitrifying organisms. It appears that less than $1 \%$ of the total COD input for S2EBPR configuration was used by OHOs (including GAOs). However, the mass balance is just based on the apparent COD transformation, while additional carbon that may have been internally generated via hydrolysis/fermentation was not included. Therefore, it is likely that some amount of additional carbon was generated in the side-stream reactor and utilized for EBPR and/or denitrification purposes.

\subsubsection{Fate of nitrogen}

$\mathrm{A} \mathrm{NO}_{3}-\mathrm{N}$ mass balance for the A2O and SSRC configurations during Phase I-B was conducted, as shown in Figure 4. In SSCR, the anaerobic side-stream reactor only received $\mathrm{NO}_{3}$ $\mathrm{N}$ from RAS, and hence had a lower $\mathrm{NO}_{3}-\mathrm{N}$ load $(\sim 104 \mathrm{~kg} \mathrm{~N} / \mathrm{d})$ than the anaerobic zone in $\mathrm{A} 2 \mathrm{O}$ configuration $(\sim 170 \mathrm{~kg} \mathrm{~N} / \mathrm{d})$, which reduced the carbon demand for denitrification and consequently benefitted PAOs. A higher amount of nitrate removal in the anoxic zone of S2EBR was observed than in the anoxic zone of A2O. This was likely because all of the carbon contained in the PE could be used for denitrification in S2EBPR configuration, while carbon was more limited in the anoxic zone of A2O configuration since it was primarily consumed in the preceding anaerobic zone for both EBPR and denitrification. The $\mathrm{NO}_{3}-\mathrm{N}$ mass balance showed that the total $\mathrm{NO}_{3}-\mathrm{N}$ removed (including assimilation) in the anoxic zone of SSCR was higher than in A2O, resulting in an additional $\mathrm{NO}_{3}-\mathrm{N}$ removed of $103 \mathrm{~kg} \mathrm{~N} / \mathrm{d}$ in the anaerobic and anoxic zones.

\section{(a) A20 configuration}

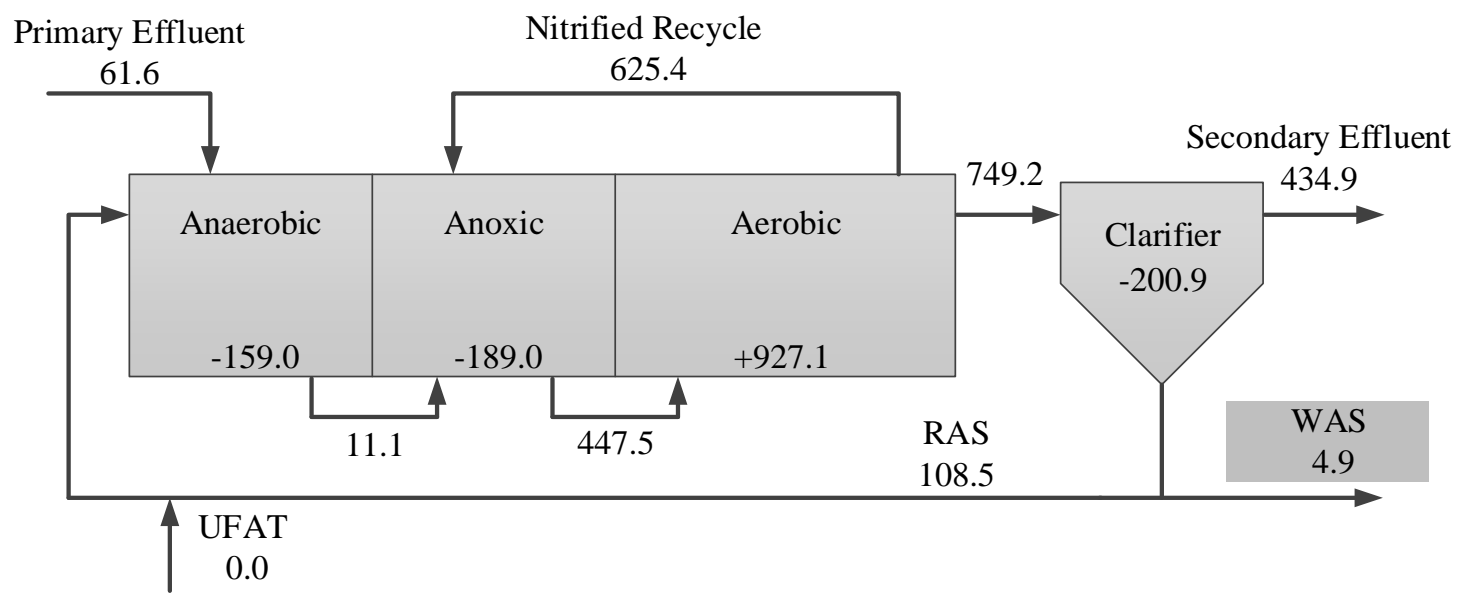




\section{(b) S2EBPR configuration}

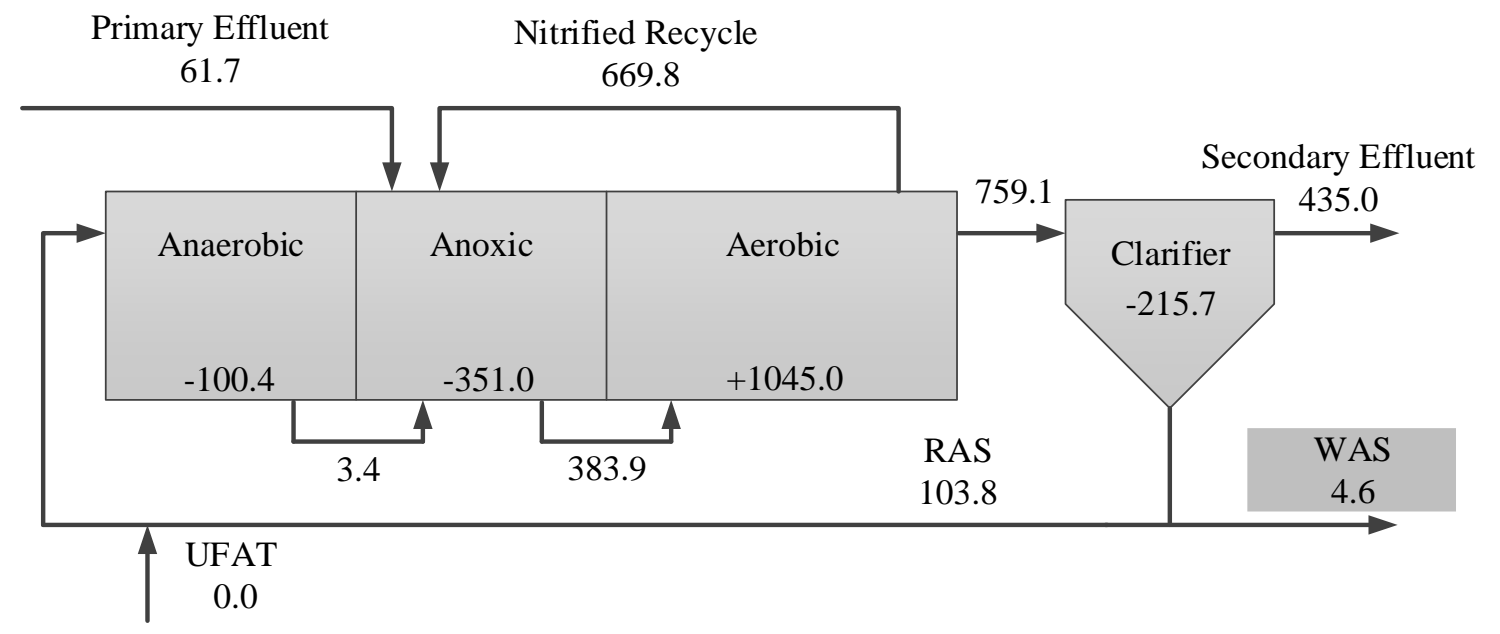

Figure 4 Fate of $\mathrm{NO}_{3}-\mathrm{N}$ in A2O and S2EBPR configurations during Phase I-B. Note: the values with plus or minus sign represent the average daily $\mathrm{NO}_{3}-\mathrm{N}$ production or removal respectively; units are in $\mathrm{kg} \mathrm{N} / \mathrm{day}$.

However, additional $\mathrm{NO}_{3}-\mathrm{N}$ was produced in the aerobic zone of S2EBPR configuration, resulting in a similar $\mathrm{SE} \mathrm{NO}_{3}-\mathrm{N}$ discharge load for both $\mathrm{A} 2 \mathrm{O}$ and $\mathrm{S} 2 \mathrm{EBPR}$ configurations. This additional $\mathrm{NO}_{3}-\mathrm{N}$ production may partially have originated from ammonia released with the RAS hydrolysis/fermentation (Ucisik and Henze, 2008) and from biomass decay (Lu et al. 2007) in the side-stream reactor, especially when the SRT was prolonged during Phase I-B. Notably, a previous research in our group showed ammonia release at an SRT of $6 \mathrm{~h}$ or less during a simulated side-stream anaerobic reactor batch testing on RAS collected from S2EBPR configuration (data not shown), and so additional ammonia load to the aerobic zone of S2EBPR configuration could be expected. However, a profile of ammonia concentrations was not conducted as part of this study, so a more precise quantification of differences in the ammonia load to the aerobic zones of A2O and S2EBPR configurations could not be performed. Additional studies to profile $\mathrm{NH}_{4}-\mathrm{N}$ and sTKN, are needed to further validate and understand impacts of $\mathrm{S} 2 \mathrm{EBPR}$ operation on $\mathrm{TN}$ removal performance.

\subsubsection{Fate of phosphorus}

$\mathrm{A} \mathrm{PO}_{4}-\mathrm{P}$ mass balance was calculated for $\mathrm{A} 2 \mathrm{O}$ and S2EBPR configurations during Phase I$\mathrm{B}$ based on measured flow rates and $\mathrm{PO}_{4}-\mathrm{P}$ concentrations in each zone (Figure 5). The average total input $\mathrm{PO}_{4}-\mathrm{P}$ load from PE $(\sim 85 \mathrm{~kg} \mathrm{P} / \mathrm{d})$ and UFAT $(\sim 1.0 \mathrm{~kg} \mathrm{P} / \mathrm{d})$ were similar in $\mathrm{A} 2 \mathrm{O}$ and $\mathrm{S} 2 \mathrm{EBPR}$ configurations, while the average $\mathrm{SE} \mathrm{PO}_{4}-\mathrm{P}$ discharge load was lower in S2EBPR configuration $(2.5 \mathrm{~kg} \mathrm{P} / \mathrm{d})$ than in A2O configuration $(9.9 \mathrm{~kg} \mathrm{P} / \mathrm{d})$. By adding the total removed $\mathrm{PO}_{4}-\mathrm{P}$ and particulate $\mathrm{P}$ together, it was estimated that the average TP/MLVSS ratio in the WAS in A2O configuration was 3.9\%, while it was $4.3 \%$ in S2EBPR configuration. This ratio was within the range of typical EBPR facilities (up to 6.2\%, Lie et al. 1997). 


\section{(a) A2O configuration}

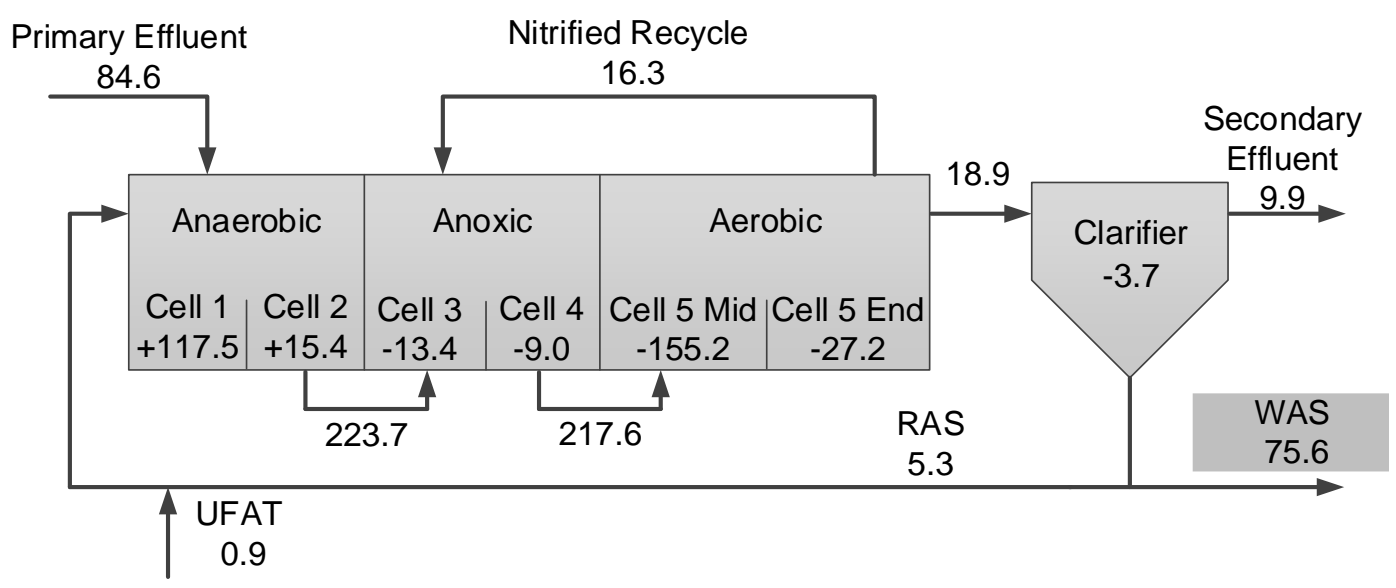

\section{(b) S2EBPR configuration}

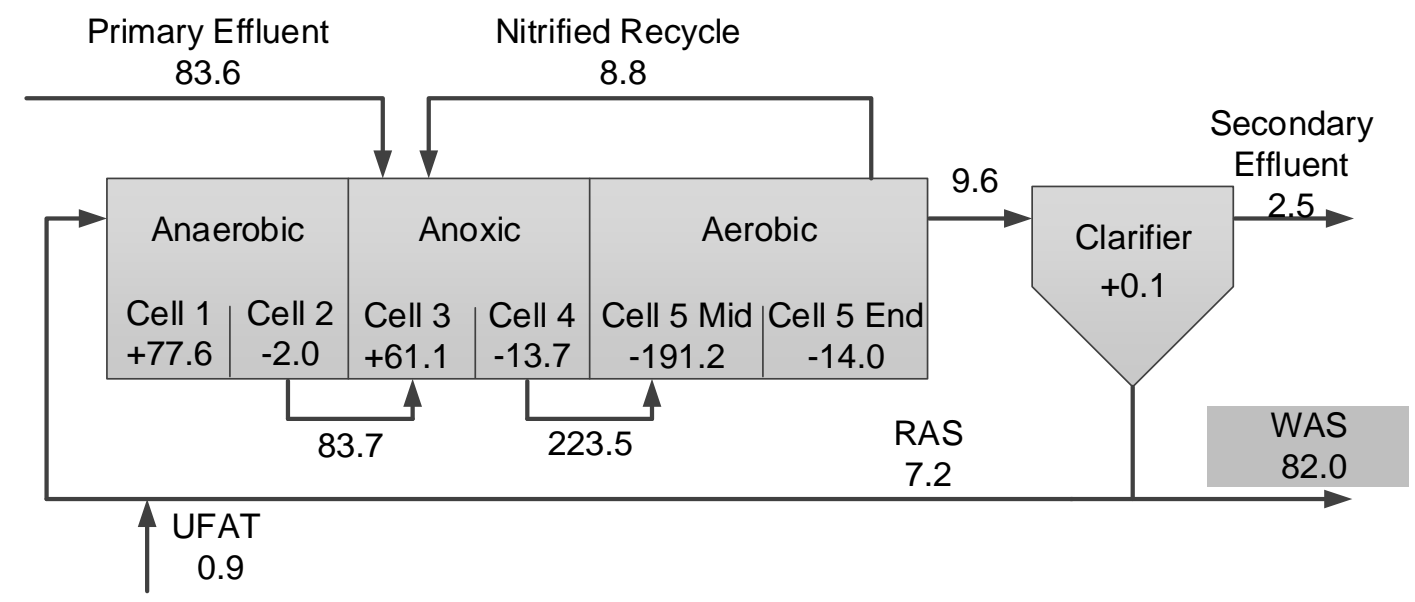

Figure 5 Fate of $\mathrm{PO}_{4}-\mathrm{P}$ in $\mathrm{A} 2 \mathrm{O}$ and S2EBPR configurations during Phase I-B. Note: the values with plus or minus sign represent the average daily $\mathrm{PO}_{4}-\mathrm{P}$ release or uptake respectively; WAS represents the $\mathrm{P}$ mass in waste activated sludge produced per day; units are in $\mathrm{kg} P /$ day.

The anaerobic $\mathrm{P}$ release in A2O configuration occurred mostly in the first anaerobic zone where the influent PE was fed. During Phase I-A, the HRT in the side-stream reactor in S2EBPR configuration $(\sim 1.6 \mathrm{~h})$ was likely inadequate for hydrolysis/fermentation to occur to an appreciable extent, which yielded lower VFA production and $\mathrm{P}$ release $(33.5 \mathrm{~kg} \mathrm{P} / \mathrm{d})$. However during Phase I-B, the intermittent mixing condition in the side-stream reactor allowed the sludge to settle creating a thick sludge layer, which could provide very low ORP conditions and potentially increase the anaerobic SRT. This allowed sufficient hydrolysis/fermentation to occur thus resulting in more VFA production, which led to an increase in P release (77.6 kg P/d). In SSRC configuration), significant $P$ release occurred in the first anoxic zone (Cell 3), and the amount released was nearly as much as in the first anaerobic zone. Phosphorus release in anoxic conditions has been reported previously (Mino et al., 1998; Guerrero et al., 2001) and also been observed in our lab-scale SBR systems (data not shown). Anoxic P release was also observed in a full-scale facility operating in a Modified Ludzack Ettinger (MLE) configuration in Singapore (Cokro et al., 2017). In that study, the authors hypothesized that non-denitrifying PAOs (nonDPAOs), which are unable to use nitrate/nitrite as electron acceptor, could recognize the anoxic condition as a pseudo-anaerobic condition. Since PE was added to the first anoxic zone of 
S2EBPR configuration, rbCOD was available in that zone, which could provide substrate for nonDPAOs, thus enhancing overall P release and substrate uptake for EBPR. Further research on the presence, activity, and metabolism of DPAOs and non-DPAOs in S2EBPR configurations are required to better understand their role in the S2EBPR process.

As a result of the combined $P$ release in the anaerobic and first anoxic zones of S2EBPR configuration, a greater total P release was observed in S2EBPR configuration $(\sim 140 \mathrm{~kg} \mathrm{P} / \mathrm{d}$ from the first anaerobic zone plus first anoxic zone) compared to the release observed in A2O configuration ( $130 \mathrm{~kg} \mathrm{P} / \mathrm{d}$ only in the anaerobic zone). This additional P release was also likely associated with greater substrate uptake (from influent plus carbon generated in the anaerobic side-stream zone), which would result in an increase in the overall P uptake under subsequent anoxic/aerobic conditions. Similar results was obtained with the in situ EBPR process profiles normalized based on the PE flow rate (Figure S1, Figure S2 and Table S5). It showed that the intermittent mixing condition in S2EBPR configuration increased the $\mathrm{P}$ release and uptake amount further, yielding a higher net $P$ removal, and removal efficiency up to $97 \%$.

\subsection{Ex situ EBPR activity and kinetics assessment}

To evaluate the ex situ EBPR activity of the activated sludge in A2O and SSRC configurations, a set of $\mathrm{P}$ release-uptake tests were conducted during Phase I-B. Typical EBPR profiles from those tests are shown in Figure $\mathrm{S} 3$. The maximum $\mathrm{P}$ release rates for both $\mathrm{A} 2 \mathrm{O}$ and S2EBPR configurations were within the range observed for other full-scale EBPR facilities, as shown in Table 4 错误!未找到引用源。 (Brdjanovic et al., 2000; Gu et al., 2008; He et al., 2008; Kuba et al., 1997a, 1997b; López-Vázquez et al., 2008). The activated sludge in S2EBPR configuration showed a higher maximum $\mathrm{P}$ release rate $(7.0 \mathrm{mg} \mathrm{P} / \mathrm{g} \mathrm{VSS} / \mathrm{h})$ than that in $\mathrm{A} 2 \mathrm{O}$ configuration ( $4.8 \mathrm{mg} \mathrm{P} / \mathrm{g} \mathrm{VSS} / \mathrm{h}$ ). Normalized P release rate has previously been used as an indicator with a positive correlation to EBPR activity (Zilles et al., 2002) and PAO relative abundance (He et al., 2008), however, it is not necessarily positively correlated with the EBPR performance in practice (Neethling et al., 2005). Although the maximum initial rates were similar, the overall average $\mathrm{P}$ uptake rate in S2EBPR configuration $(4.3 \pm 0.5 \mathrm{mg} \mathrm{P} / \mathrm{g} \mathrm{VSS} / \mathrm{h})$ was two times higher than in $\mathrm{A} 2 \mathrm{O}$ configuration, indicating a higher $\mathrm{P}$ uptake amount.

Table 4 Comparison of specific kinetic rates observed in ex situ $\mathrm{P}$ release and uptake batch tests between A2O and S2EBPR configuration during Phase I-B.

\begin{tabular}{|c|c|c|c|c|c|c|c|c|}
\hline \multirow{2}{*}{ Configuration } & \multicolumn{2}{|c|}{$\mathrm{P}_{\text {rel }}$} & \multicolumn{2}{|c|}{$\mathrm{VFA}_{u p}{ }^{\mathrm{g}}$} & \multicolumn{2}{|c|}{$\mathrm{P}_{\mathrm{up}}$} & \multicolumn{2}{|c|}{$\mathrm{P}_{\mathrm{up}} / \mathrm{P}_{\text {rel }}$} \\
\hline & Max & Avg. & $\operatorname{Max}$ & Avg. & Max & Avg. & Max & Avg. \\
\hline A2O & $4.8 \pm 0.5$ & $2.2 \pm 0.6$ & $22 \pm 3$ & $14 \pm 0$ & $2.1 \pm 0.2$ & $2.3 \pm 1.1$ & $0.43 \pm 0.00$ & $0.43 \pm 0.11$ \\
\hline S2EBPR & $7.0 \pm 0.5$ & $3.4 \pm 0.4$ & $19 \pm 12$ & $14 \pm 4$ & $2.8 \pm 1.7$ & $4.3 \pm 0.5$ & $0.40 \pm 0.28$ & $0.54 \pm 0.01$ \\
\hline Modified UCT ${ }^{\mathrm{a}, \mathrm{b}, \mathrm{c}}$ & NA & NA & $7-47$ & NA & $4-19.2$ & NA & NA & NA \\
\hline Phoredox ${ }^{c}$ & NA & NA & $11-21$ & NA & $6.2-9.1$ & NA & NA & NA \\
\hline $\begin{array}{c}\text { PhoStrip } \\
\text { (sidestream) }^{\mathrm{c}, \mathrm{d}}\end{array}$ & NA & NA & $9-23$ & NA & $2.2-9.8$ & NA & NA & NA \\
\hline $\begin{array}{l}\text { Full-scale EBPR } \\
\text { facilities }^{\mathrm{e}, \mathrm{f}}\end{array}$ & $5.6-31.9$ & NA & $16-42$ & NA & $\begin{array}{l}1.9- \\
11.0\end{array}$ & NA & $0.25-0.69$ & NA \\
\hline
\end{tabular}

$\mathrm{P}_{\text {rel: }}$ specific P release rate (mg P/g VSS/h); $\mathrm{VFA}_{\text {up }}$ : specific acetate uptake rate (mg HAc/g VSS/h); $\mathrm{P}_{\text {up: }}$ : specific P uptake rate (mg P/g VSS/h); UCT: University of Cape Town; Phoredox: phosphorus reduction oxidation; PhoStrip: phosphorus stripping; NA: not available; ${ }^{\text {a }}$ (Kuba et al., 1997a); ${ }^{\text {b: }}$ (Kuba et al., 1997b); ' : (López-Vázquez et al., 2008); d: (Brdjanovic et al., 2000); e: (Gu et al., 2008); $:$ (He et al., 2008). 
Table 错误! 文档中没有指定样式的文字。Comparison of stoichiometric ratios observed in ex situ P release and uptake batch tests between A2O and S2EBPR configuration during Phase I-B.

\begin{tabular}{|c|c|c|c|c|c|}
\hline Configuration & $\mathrm{P} / \mathrm{HAc}$ & PHA/HAc & Glyc/HAc & P/PHA & Glyc/PHA \\
\hline $\mathrm{A} 2 \mathrm{O}$ & $0.22 \pm 0.06$ & $0.53 \pm 0.21$ & $0.16 \pm 0.03$ & $0.29 \pm 0.23$ & $0.66 \pm 0.60$ \\
\hline S2EBPR & $0.45 \pm 0.27$ & $0.41 \pm 0.23$ & $0.22 \pm 0.02$ & $0.87 \pm 0.16$ & $0.74 \pm 0.16$ \\
\hline $\begin{array}{l}\text { Full-scale side-stream EBPR } \\
\text { facilities }^{\text {a,b }}\end{array}$ & $0.7-1.3$ & $1.07-1.64$ & $0.21-0.48$ & $0.6-0.9$ & $0.3-0.4$ \\
\hline $\begin{array}{l}\text { Full-scale conventional EBPR } \\
\text { facilities }^{\text {a,b }}\end{array}$ & $0.27-1.06$ & $0.67-2.10$ & $0.02-0.82$ & $0.2-1.9$ & $0.2-1.2$ \\
\hline Lab-scale PAO culture ${ }^{\mathrm{c}, \mathrm{d}}$ & 0.50 & 1.22 & 0.50 & 3.68 & 0.90 \\
\hline Lab-scale GAO culture ${ }^{\mathrm{e}}$ & NA & 1.86 & 1.12 & NA & 0.95 \\
\hline PAO model-TCA cycle pathway, ${ }^{c, f}$ & 0.8 & 0.89 & 0.0 & \multirow{2}{*}{0.41} & \multirow{2}{*}{0.42} \\
\hline PAO model-glycolysis pathway ${ }^{\mathrm{c}, \mathrm{f}}$ & 0.5 & 1.33 & 0.5 & & \\
\hline GAO model ${ }^{\mathrm{e}}$ & 0.0 & 1.85 & 1.12 & NA & 0.65 \\
\hline
\end{tabular}

P/HAc: P release to acetate uptake ratio (P-mol/C-mol); PHA/HAc: PHA production to acetate uptake ratio (C-mol/C-mol); Glyc/HAc: glycogen utilization to acetate uptake ratio (C-mol/C-mol); P/PHA: PolyP formation to PHA consumption ratio (P-mol/C-mol); Glyc/PHA: glycogen formation to PHA consumption ratio (C-mol/C-mol); NA: not available; TCA: tricarboxylic acid cycle; ${ }^{\text {a: }}$ (Lanham et al., 2013a); ${ }^{\text {b: (Gu et }}$

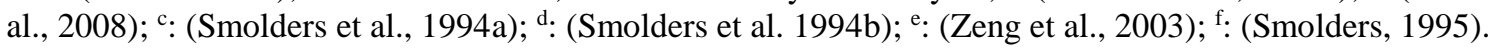

The $\mathrm{P}$ release/HAc uptake $(\mathrm{P} / \mathrm{HAc})$ ratio is often used as an indicator of the relative PAO and GAO activities and abundance. As illustrated in Table 5, the P/HAc in S2EBPR configuration was $0.45 \mathrm{P}-\mathrm{mol} / \mathrm{C}-\mathrm{mol}$, which is similar to the value for PAOs relying on glycolysis for generation of reducing equivalents under anaerobic conditions (Smolders et al. 1994a). In comparison, a much lower P/HAc ratio (0.22 P-mol/C-mol) was observed in A2O configuration, which potentially indicates the presence of GAOs.

The PHA generation/HAc uptake ratios (PHA/HAc ratio) observed in this study were lower than the values predicted in PAO and GAO models, which may be related to the involvement of Tetrasphaera and other heterotrophic bacteria that may take up acetate without storing it as PHA (Marques et al. 2017; Kristiansen et al., 2013).

The glycogen utilization/HAc uptake ratios (Gly/HAc ratio) for A2O and S2EBPR configurations ranged from 0.14 to $0.23 \mathrm{C}$-mol/C-mol, which were within the range between TCA cycle and glycolysis activity, as reported in other full-scale EBPR facilities (Gu et al., 2008; Lanham et al., 2013a). The relatively higher ratio observed in S2EBPR configuration could be related to an increase in the use of glycolysis pathway over TCA cycle. The preferential use of glycolysis is considered more efficient for EBPR through production of additional PHA per substrate uptake (Smolders et al. 1994a). Increased reliance on glycolysis was also observed in several S2EBPR facilities in Denmark (Lanham et al., 2013a). An increased reliance on glycolysis, taken together with the higher TP/MLVSS content, indicates that the S2EBPR configuration involves PAO-dominated metabolism, primarily relying on the glycolysis pathway.

The $\mathrm{P}$ uptake/PHA utilization ratio (P/PHA ratio) in A2O configuration (0.29 P-mol/C-mol) was lower than that in the PAO model, which may be related to a higher relative abundance of GAOs in the sludge. On the contrary, the P/PHA ratio in S2EBPR configuration $(0.87 \mathrm{P}-\mathrm{mol} / \mathrm{C}$ mol) was nearly 3 times higher than in A2O configuration, indicating a higher $\mathrm{P}$ uptake capacity in the full-scale sludge containing possibly not only Accumulibacter but also other PAOs (e.g., Tetrasphaera) that do not rely on PHA for P uptake (Lanham, et al. 2013a). 


\subsection{Microbial dynamics}

To identify the bacteria that contained polyP, DAPI staining was conducted throughout pilot testing. As shown in Figure 6(a), the abundance of DAPI-stained PAOs (total PAOs of all bacteria targeted by DAPI stain) was observed within the range of 5.8\%-18.2\%. The average total PAO abundance in S2EBPR configuration was greater than in A2O configuration, indicating a higher polyP accumulating capacity.
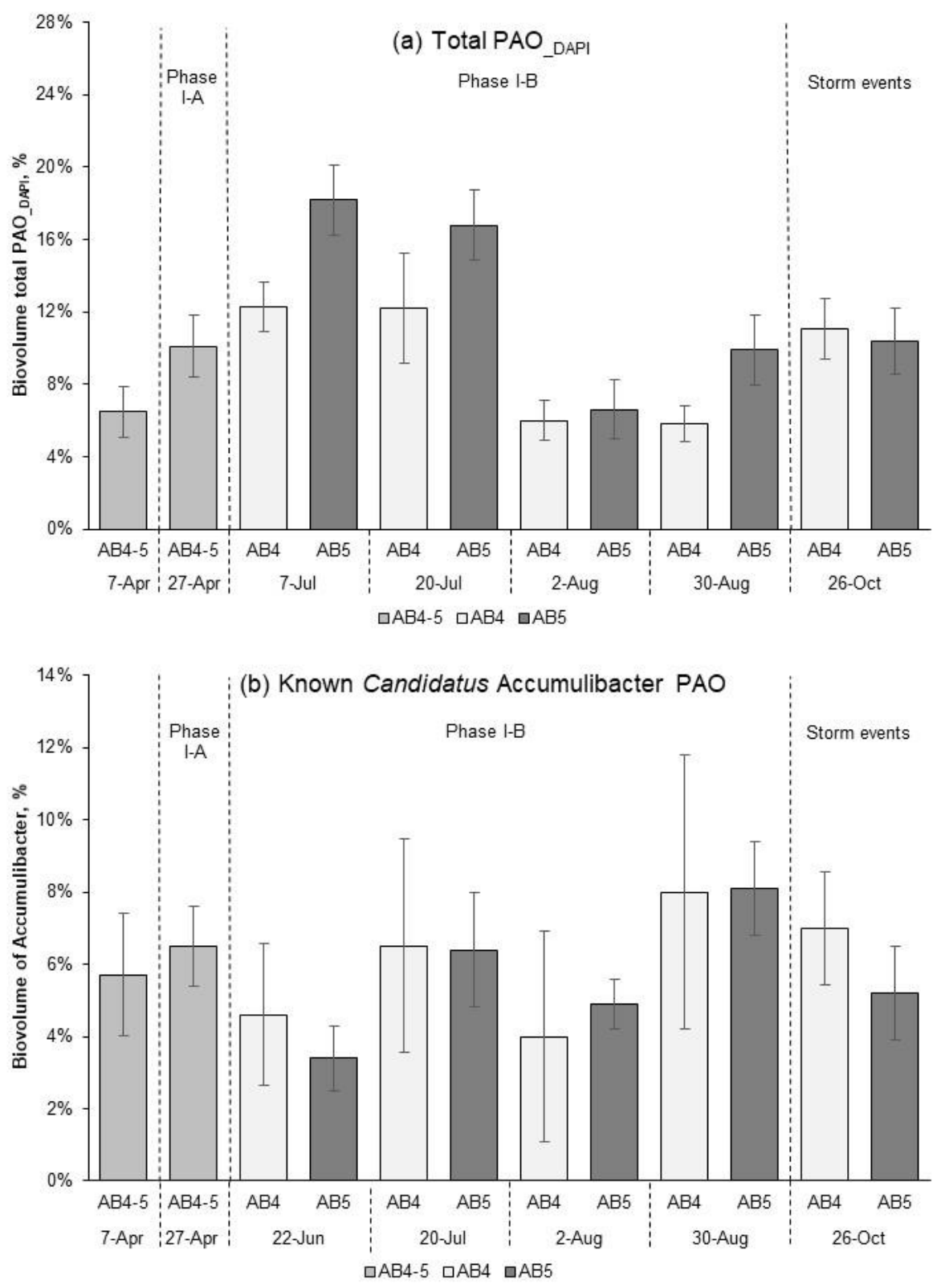

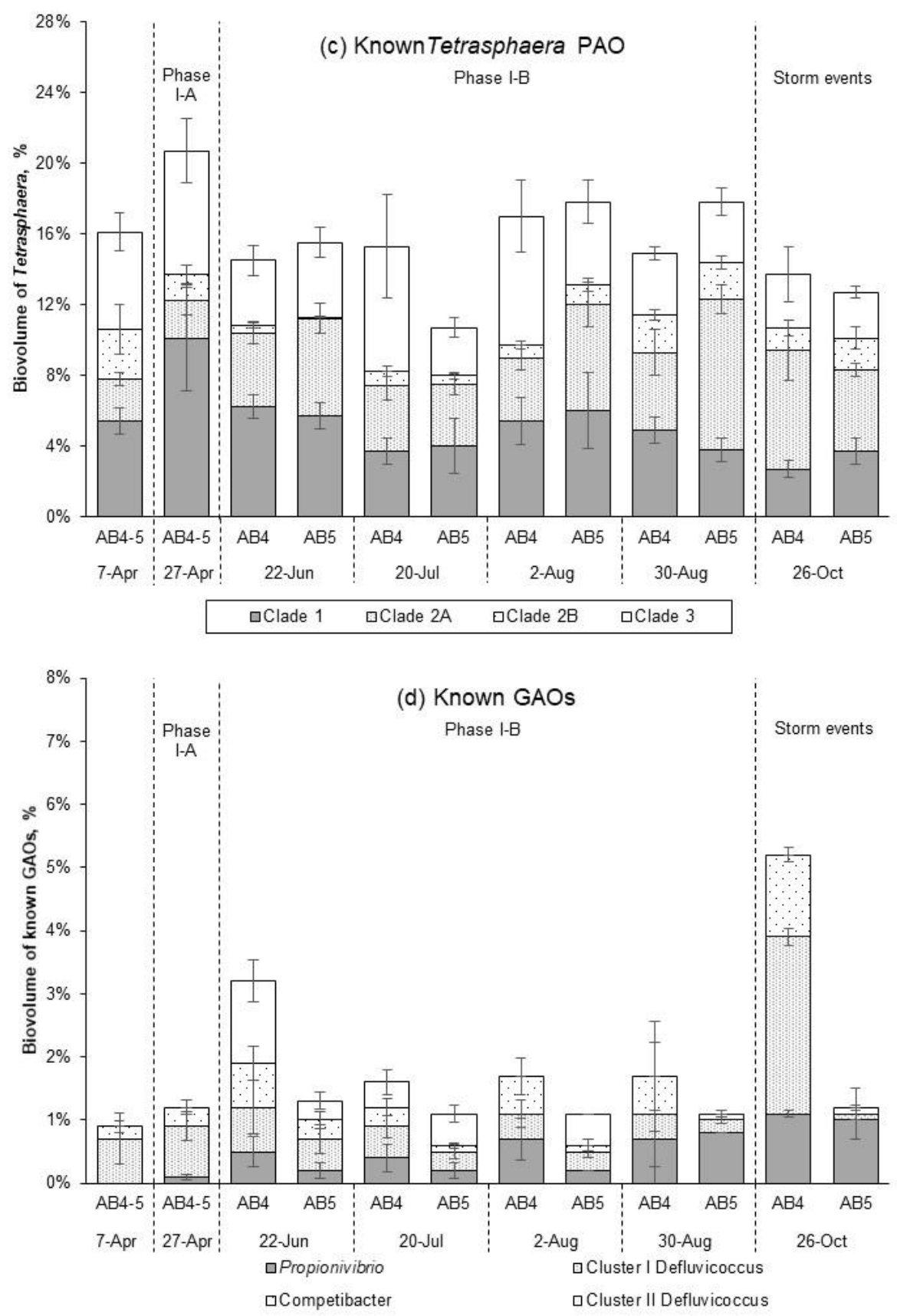

Figure 6 Biovolume of (a) total PAOs quantified by DAPI polyP staining, (b) Accumulibacter (PAO651, PAO462b, PAO846b), (c) Tetrasphaera (Tet1-266, Tet2-174, Tet2-892, and Tet3-654), and (d)

Competibacter (GAOmix: GB742, GAOQ431, GAOQ989), Defluvicoccus (DF1mix: TFO_DF218, TFO_DF618; DF2mix: DF988, DF1020), and Propionivibrio (Prop207) quantified by FISH in A2O and S2EBPR configurations during pilot testing. Error bars indicate standard errors.

When using 16S rRNA gene-based FISH probes to quantify the biovolume of key functionally relevant populations, however, no significant difference in relative abundance of Accumulibacter was observed between A2O (5.78 $\pm 1.58 \%)$ and S2EBPR configuration (5.70 \pm $1.74 \%$ ) during pilot testing (Figure 6(b)). During Phase I-B, the relative abundance of Accumulibacter gradually increased in both A2O and S2EBPR configurations. After the end of 
Phase I-B, a decrease in Accumulibacter occurred, as a result of unsteady state conditions caused by the storm events. Given that the total abundance of PAOs was higher in S2EBPR configuration than in $\mathrm{A} 2 \mathrm{O}$ configuration, while the relative abundance of Accumulibacter did not show significant differences between A2O and S2EBPR configuration, implies that there are other non-Accumulibacter PAOs in the system. These non-Accumulibacter PAOs are likely in greater abundance in S2EBPR configuration than in A2O configuration. Consequently, there are likely other factors, such as microbial structure, PAO phenotypic diversity and elasticity, and shift in metabolic pathways that could have led to the observed differences in EBPR performance.

Tetrasphaera, another important group of putative PAOs capable of fermenting complex carbon sources (e.g. glucose and amino acid) (Marques et al. 2017; Kristiansen et al., 2013), were present in higher relative abundance (ranging from 10.7\% to 20.7\%) than Accumulibacter (Figure 6(c)), which is consistent with previous reports on full-scale EBPR systems (Lanham et al., 2013a; Stokholm-Bjerregaard et al., 2017). Three Tetrasphaera-related clades, including Clade 1, Clade 2A, and Clade 3 were dominant in the culture at similar relative abundances. Although Tetrasphaera Clade 1 and a portion of Clade 3 cannot take up acetate, they are all capable of fermentation, which leads to Tetrasphaera thriving in WRRFs that receive complex organic matter (Nguyen et al., 2011, 2015). In the side-stream reactor of an S2EBPR system, it is likely that Tetrasphaera may play a crucial role that firstly fermenting complex carbon sources for energy generation, and Accumulibacter could then take up the fermentation products (e.g., acetate or propionate) generated by Tetrasphaera for PHA storage. Further studies are warranted to better understand the coexistence and synergy between Accumulibacter and Tetrasphaera in S2EBPR systems.

FISH-targeted GAOs were present in much lower relative abundance than PAOs in both A2O and S2EBPR configurations, ranging from $0.9 \%$ to 5.2\% (Figure 6(d)). Cluster I Defluviicoccus and Propionivibrio were the most frequently observed GAOs. Although few known GAOs were detected in either system, the relative abundance of GAOs in A2O configuration was always greater than in S2EBPR configuration. It should also be noted that a significant increase in the GAO population was observed in the A2O configuration on October 26, especially Cluster I Defluviicoccus and Competibacter. Many studies have demonstrated that Defluviicoccus and Competibacter are capable of competing with PAOs for uptake of acetate and propionate under anaerobic conditions (Crocetti et al., 2002; Dai et al., 2007; Oehmen et al., 2005). The observed proliferation of GAOs after storm events may have contributed to the observed deterioration in performance during this period.

Higher-resolution phylogenetic and phenotypic comparison of the microbial community structures between A2O and S2EBPR configuration were further invested with 16s rRNA gene amplicon sequencing. Sampling of the aerobic MLSS was performed before the pilot testing was started $(n=2)$ and during the testing $(n=5)$ for each of the treatment trains and the 16S rRNA gene was amplified and sequenced. Non-metric multidimensional scaling (NMDS) analysis was performed to determine the relationship between the configuration and the microbial communities. The samples, taken before the pilot was started, clustered separately while the samples at the beginning of the pilot (June 22) clustered very closely together (Figure 2). This is probably due to the fact that the MLSS was mixed together and redistributed to the two trains at the beginning of the pilot. During the piloting, the microbial communities in the two treatment trains diverged as the communities became acclimated to the different configurations (Figure 7). A comparison between the treatment trains at each sampling date suggests that the communities became more dissimilar to each other as the piloting progressed. After more than 3 months of piloting, the communities were the most dissimilar to each other on August 30. A low stress value of 0.04 for the NMDS analysis suggests that the analysis was robust. 


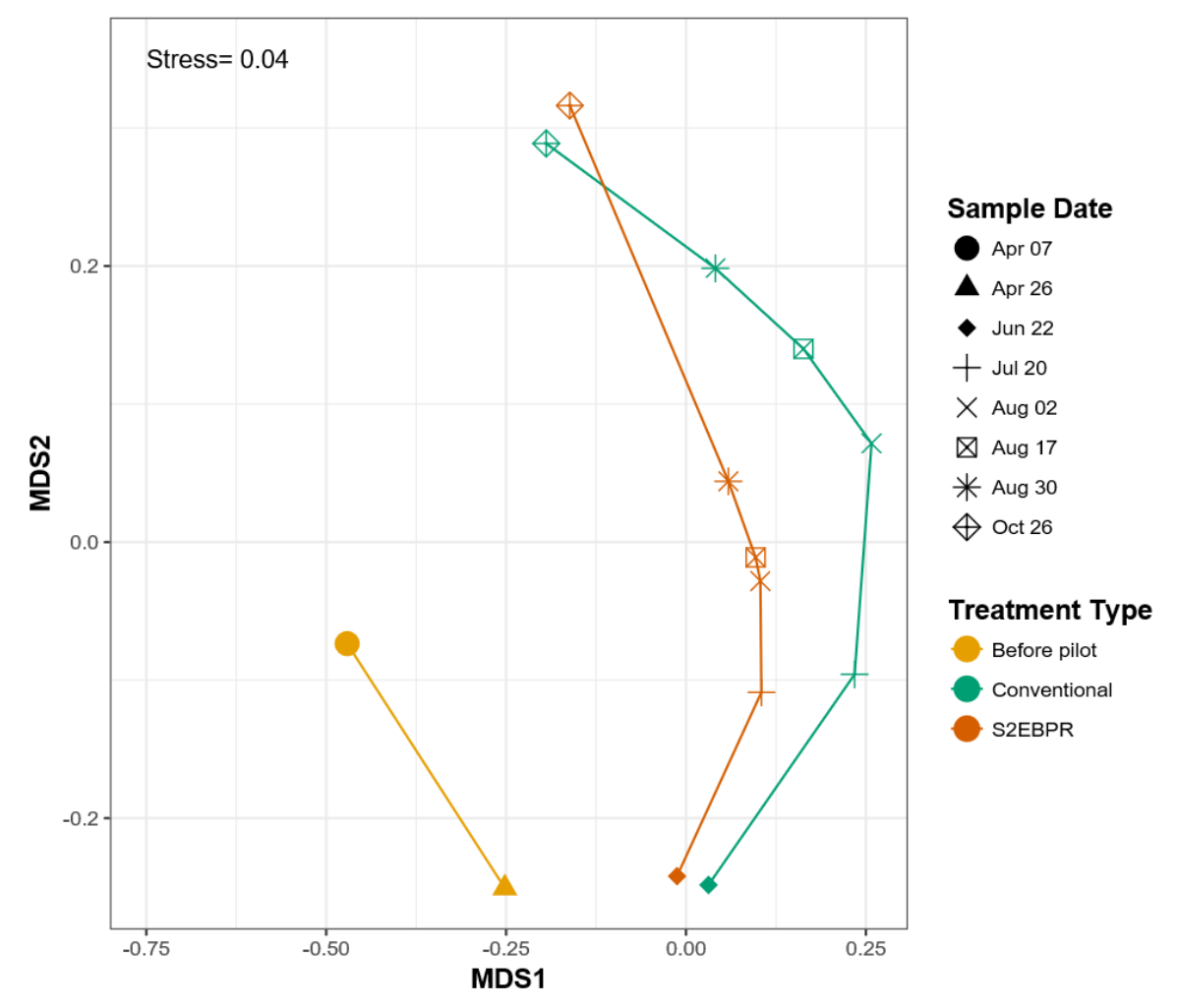

Figure 7 Non-metric Multidimensional Scaling (NMDS) analysis of the whole communities in A2O and S2EBPR configurations during pilot testing.

We also performed an OTU-level analysis to determine taxa specific to the treatment trains. The distribution of OTUs among the two treatment trains were categorized as follows: (i) OTUs that are common to both trains, (ii) OTUs that are unique to $\mathrm{A} 2 \mathrm{O}$, (iii) OTUs that are unique to S2EBPR. A core community, in this study, is defined as OTUs that were greater than $0.1 \%$ abundant and present in all samples under consideration. Core communities were determined for both treatment trains and categorized as mentioned above. There were a total of 57 OTUs that were common between the two treatment trains (Figure S6). OTUs that were classified as Rhodocylaceae, Haliangieaceae, Xanthomonadaceae, and Comamonadaceae were the most abundant of the common core OTUs and included $\mathrm{Ca}$. Accumulibacter (OTU00015). Of the core community in each of the trains, 14 OTUs were exclusively present in the A2O community while S2EBR had 35 OTUs there were exclusively present. This suggests that S2EBPR gave rise to more unique OTUs that were exclusively part of its core community. Some of the most abundant OTUs exclusive to S2EBPR were classified as Nannocystaceae, Moraxallaceae, Haliangiaceae, Rhodocyclaceae, and Nitrospiraceae. Organisms in the Rhodocyclaceae and Nitrispiracea families are known to be involved in $\mathrm{P}$ and $\mathrm{N}$ removal processes and could be important to biological nutrient removal (BNR). The main difference between A2O and S2EBPR system is the addition of a side-stream reactor to enable hydrolysis/fermentation and act as a source of easily assimilable carbon in the form of VFAs. So it is plausible that the presence of continuous production and supply of readily assimilable VFAs can enable a wider diversity of organisms to grow. The observation that S2EBPR core communities consist of more exclusive OTUs compared to $\mathrm{A} 2 \mathrm{O}$ is interesting and warrants more focused studies. 


\section{Discussion}

\subsection{Impacts of influent carbon and C/P ratio}

PAOs have the ability to take up excess phosphate to produce intracellular polyP, which relies on the anaerobic storage of intracellular metabolites (e.g., PHA for Accumulibacter, glycogen for Tetrasphaera) from utilization of carbon (Mino et al. 1998; Smolders et al. 1994a; Wentzel et al. 1989; Kristiansen et al. 2013). Therefore, the carbon supply in wastewater influent and the amount of available VFA for P removal play important roles in successful EBPR processes. Figure S4 shows the VFA inputs from PE and UFAT during the pilot testing. It was observed that the VFA supply from PE fluctuated during Phase I-A, and was more stable during Phase I-B. The VFA load from UFAT had a slight increasing trend but it was relatively stable throughout the testing period.

Table S6 summarizes the COD/P and VFA/P ratios in the influent. Recommendations for influent carbon/P ratios vary depending on which parameter is being measured. Randall et al. (1998) recommended a minimum COD/TP ratio of 40:1 to achieve effluent phosphorus concentrations of $1 \mathrm{mg} / \mathrm{L}$ or less. However, Oehmen et al. (2007) pointed out that a COD/P ratio greater than 50:1 tends to favor growth of GAOs, and recommended a lower COD/P ratio ranging from 10:1-20:1. Compared to the COD/P ratio, the $\mathrm{rbCOD} / \mathrm{P}$ ratio is more reliable to indicate the EBPR performance since adequate supply of readily biodegradable carbon compounds in the anaerobic zone is critical for EBPR. The minimum $\mathrm{rbCOD} / \mathrm{P}$ ratio for satisfying $\mathrm{P}$ removal in WRRFs was recommended as 15:1-25:1 (Gu et al., 2008; Randall et al., 1998; Tetreault et al., 1986), while the VFA/P was recommended as 15:1 (Coats et al., 2017). During this pilot study, even though high $\mathrm{COD} / \mathrm{TP}(72 \pm 9)$ and $\mathrm{COD} / \mathrm{PO}_{4}-\mathrm{P}(80 \pm 22)$ ratios were observed in the primary effluent, the VFA/TP ratio was low $(4.6 \pm 3.7)$. Therefore, the VFA supply from PE only may not have been sufficient for the conventional EBPR configuration to achieve effective EBPR performance. Thus, additional carbon from UFAT was added, thus increasing the VFA/ $/ \mathrm{PO}_{4}-\mathrm{P}$ ratio in the anaerobic zone of A2O configuration from 5:1 to 10:1 (Table S7).

Even though half of the VFA input for S2EBPR configuration was diverted to mainstream process with PE, RAS hydrolysis/fermentation in the side-stream reactor, especially during Phase I-B under intermittent mixing condition, likely contributed additional carbon for EBPR. Based on the $\mathrm{C}$ and $\mathrm{P}$ mass balances, and measured $\mathrm{P}$ release to total acetate uptake ratio in ex situ batch testing, it was estimated that $\sim 180 \mathrm{~kg} \mathrm{COD} / \mathrm{d}$ of VFA could be generated continuously via fermentation in the side-stream reactor. Therefore, the influent $\mathrm{C} / \mathrm{P}$ ratio in the influent is less indicative of the potential EBPR performance in S2EBPR process due to the partial decoupling of P-release and uptake, separated carbon/phosphorus inputs, and additional VFA generation through hydrolysis/fermentation in the side-stream reactor. In general, both the influent $\mathrm{C} / \mathrm{P}$ ratios and the sustained and steady VFA feeding associated with RAS fermentation in the side-stream reactor should be considered as an impact factor on S2EBPR performance and prevalence of PAOs. This would directly impact PHA accumulation along with P-release in the anaerobic zones which would affect P-uptake in the aerobic zone. The optimum proportion of RAS diversion and conditions in the side-stream reactor for S2EBPR still need further investigation.

\subsection{Impacts of VFA composition}

In addition to the $\mathrm{C} / \mathrm{P}$ ratio and carbon input, different available carbon sources (e.g. VFAs, glucose, and amino acids) could also have an impact on the PAO-GAO competition in EBPR (López-Vázquez et al., 2009). The VFA composition in the primary effluent and in the UFAT is shown in Figure S5. The proportion of propionate in the UFAT overflow (35\%) was higher than in the PE (24\%). The relative proportions of VFAs in the UFAT overflow were also more 
consistent than those measured in the PE. Previous studies indicated that VFA uptake rates of PAOs were similar using either acetate or propionate as carbon sources, while GAOs seem to have different preferences (Shen \& Zhou 2016; Dai et al. 2007; Oehmen et al. 2006). VFA feeding strategies such as switching use of acetate/propionate (Lu et al., 2006), dosing VFA slowly and continuously (Tu and Schuler, 2013), feeding a combination of acetate and propionate (López-Vázquez et al., 2009), and propionate-feeding under different C/P ratios (Broughton et al., 2008) were found to enrich lab-scale reactors with Accumulibacter, while excluding GAOs. For full-scale WRRFs, such strategies might not always be feasible due to diurnal and seasonal variability of influent. However, the S2EBPR process provides several of the above mentioned strategies such as continuous and slow VFA feeding through RAS fermentation and VFA production and a relatively higher proportion of propionate over acetate. Therefore, the conditions in the S2EBPR process could provide a competitive advantage to PAOs over GAOs.

\subsection{Impacts of retention time}

The key feature of S2EBPR is the implementation of a side-stream anaerobic biological sludge hydrolysis and fermentation reactor. Therefore the design and operation of the side-stream reactor will have a major impact on VFA generation rate and thus achieving effective and stable EBPR performance. Because of shifting PE flow from anaerobic zone to anoxic zone in S2EBPR configuration, only UFAT and RAS entered the side-stream reactor, which resulted in an anaerobic HRT that was 2-3 times greater than the anaerobic HRT in A2O configuration (Table S8). An extended HRT in the anaerobic zone is generally regarded as favorable for P-removal performance (Coats et al., 2011). As hydrolysis/fermentation is one of the rate-limiting steps, an extended contact/reaction time in side-stream reactor would benefit the fermenting microorganisms to break down complex carbon compounds into VFA, and facilitating VFA uptake and PHA storage by Accumulibacter-related PAOs.

Besides the external carbon supply from UFAT, the retained sludge itself could be treated as a potential carbon source in the side-stream reactor. Therefore, the anaerobic SRT in the sidestream reactor should be an important factor for S2EBPR either with or without additional VFA supplement. During Phase I-A, the SRT in the side-stream reactor was the same as the HRT when the anaerobic zone was completely mixed. During Phase I-B, when the mixers were only turned on intermittently, the anaerobic SRT was expected to be much longer than the HRT. Although it was difficult to quantify the actual SRT with intermittent mixing, the anaerobic SRT could be estimated to be much longer than the one in the conventional anaerobic zone. This extended anaerobic SRT, along with a higher sludge concentration in the side-stream reactor, would have increased production of VFA via fermentation, maximized VFA uptake and PHA storage of Accumulibacter-related PAOs, and eventually enhanced P uptake capacity in subsequent anoxic/aerobic zones. Additionally, it was previously observed that Accumulibacter-related PAOs are able to maintain acetate uptake activity under extended anaerobic conditions ( $>12 \mathrm{~h}$ ) while Competibacter-related GAOs are either unable to maintain activity or cannot survive without external substrate addition (Nielsen et al., 2014). This has been attributed to the difference in availability of various intracellular polymers, energy requirements for maintenance, and cell decay rates (Lu et al., 2006, López-Vázquez et al. 2008, Hao et al., 2010). Tetrasphaera-type PAOs, capable of fermenting different organic substrates, would also benefit from the conditions in side-stream reactor. As a result of decay of GAOs and other OHOs, PAOs could have a competitive advantage in the side-stream reactor where there is an extended anaerobic retention time ( $>12 \mathrm{~h}$ ) and result in a higher EBPR activity and/or relative abundance in S2EBPR systems. It is, therefore, critical to have sufficient anaerobic solids retention time in the side-stream reactor. 
The SRT in the aerobic zone is also an important design parameter in EBPR affecting the PAO-GAO competition (López-Vázquez et al., 2009). The aerobic SRT should be long enough to oxidize PHA stored in the anaerobic stage (Brdjanovic et al., 1998), while longer SRTs could lead to GAO-domination (Rodrigo et al., 1999). Whang \& Park (2006) also observed the microbial community switching from GAO-domination to PAO-domination under shorter SRT (3 days), since the growth rate of GAOs was lower than PAOs. The aerobic SRT in both A2O and S2EBPR configurations was approximately 5 days, which was appropriate for growth of Accumulibacter.

\section{Conclusion}

The full-scale pilot testing with side-by-side operation of an S2EBPR configuration (SSRC process) and a conventional EBPR configuration (A2O process) was conducted at the Rock Creek Facility to evaluate changes in EBPR performance and investigate mechanisms involved:

1. With the same influent wastewater characteristics, the S2EBPR configuration had more effective and stable phosphorus removal performance than conventional EBPR, especially when the mixers in side-stream reactor were operated intermittently.

2. For successful S2EBPR system operation, adequate anaerobic SRT and conditions that generate continuous and slow feeding/production of VFA with higher composition percentage of propionate in the side-stream reactor of S2EBPR process likely provide a competitive advantage for PAOs over GAOs.

3. Mass balance analysis indicated that side-stream RAS-fermentation produced additional $42 \%$ of carbon in PE for supporting phosphorus removal and denitrification.

4. EBPR activity assessment showed a relatively higher PAO activity in S2EBPR configuration, and an increased degree of dependence on glycolysis pathway than TCA cycle.

5. Analysis of functionally relevant populations suggested that there was no significant difference in the relative abundances of Accumulibacter and Tetrasphaera-related PAOs between the two configurations. However, lower relative abundance of known GAOs was observed in S2EBPR configuration than the conventional configuration.

Further studies, such as involvement of Tetrasphaera, optimization of side-stream reactor conditions, percentage of RAS diversion for fermentation, and more in-depth and higherresolution investigation of microbial ecology at finer resolution and corresponding characterization of phenotypic traits, are required to develop design criteria and better understand the mechanisms underlying the improved performance of S2EBPR systems.

\section{References}

Albertsen, M., Karst, S.M., Ziegler, A.S., Kirkegaard, R.H., Nielsen, P.H., 2015. Back to basics - The influence of DNA extraction and primer choice on phylogenetic analysis of activated sludge communities. PLoS One. 10: e0132783.

Andreasen, K., Petersen, G., Thomsen, H., Strube, R., 1997. Reduction of nutrient emission by sludge hydrolysis. Water Sci. Technol. 35, 79-85. https://doi.org/10.1016/S0273-1223(97)00215-1

Barnard, J.L., Abraham, K., 2006. Key features of successful BNR operation. Water Sci. Technol. 53, 1-9. https://doi.org/10.2166/wst.2006.400

Barnard, J.L., Dunlap, P., Steichen, M., 2016. Rethinking the Mechanisms of Biological Phosphorus Removal, in: Proceedings of IWA/WEF Nutrient Removal and Recovery Conference. Denver, CO.

Brdjanovic, D., Loosdrecht, M.C.M. Van, Hooijmans, C.M., Alaerts, G.J., Heijnen, J.J., 1998. Minimal Aerobic Sludge Retention Time in Biological Phosphorus Removal Systems. Biotechnol. Bioeng. 60, 326-332.

Brdjanovic, D., van Loosdrecht, M.C.M., Versteeg, P., Hooijmans, C.M., Alaerts, G.J., Heijnen, J.J., 2000. 
Modeling COD, N AND P REMOVAL in a Full-Scale WWTP Haarlem Waarderpolder. Water Res. 34, 846-858.

Broughton, A., Pratt, S., Shilton, A., 2008. Enhanced biological phosphorus removal for high-strength wastewater with a low rbCOD:P ratio. Bioresour. Technol. 99, 1236-1241. https://doi.org/10.1016/j.biortech.2007.02.013

Carvalho, G., Lemos, P.C., Oehmen, A., Reis, M.A.M., 2007. Denitrifying phosphorus removal: Linking the process performance with the microbial community structure. Water Res. 41, 4383-4396. https://doi.org/10.1016/j.watres.2007.06.065

Coats, E.R., Brinkman, C.K., Lee, S., 2017. Characterizing and contrasting the microbial ecology of laboratory and full-scale EBPR systems cultured on synthetic and real wastewaters. Water Res. 108, 124-136. https://doi.org/10.1016/j.watres.2016.10.069

Coats, E.R., Watkins, D.L., Brinkman, C.K., Loge, F.J., 2011. Effect of anaerobic HRT on biological phosphorus removal and the enrichment of phosphorus accumulating organisms. Water Environment Research, 83(5), 461-469.

Cokro, A.A., Law, Y., Williams, R.B.H., Cao, Y., Nielsen, P.H., Wuertz, S., 2017. Non-denitrifying polyphosphate accumulating organisms obviate requirement for anaerobic condition. Water Res. 111, 393-403. https://doi.org/10.1016/j.watres.2017.01.006

Copp, J.B., Belk, I., Vale, P., 2012. Operational Control of a RAS Fermentation Process for Enhancing Biological Phosphorus Removal, in: WEFTEC 2012. pp. 6056-6068.

Cordell, D., Drangert, J. O., White, S., 2009. The story of phosphorus: global food security and food for thought. Global environmental change, 19(2), 292-305.

Crocetti, G.R., Banfield, J.F., Keller, J., Bond, P.L., Blackall, L.L., 2002. Glycogen-accumulating organisms in laboratory-scale and full-scale wastewater treatment processes. Microbiology 148, 3353-3364.

Dai, Y., Yuan, Z., Wang, X., Oehmen, A., Keller, J., 2007. Anaerobic metabolism of Defluviicoccus vanus related glycogen accumulating organisms (GAOs) with acetate and propionate as carbon sources. Water Res. 41, 1885-1896. https://doi.org/10.1016/j.watres.2007.01.045

Daims, H., Lücker, S., Wagner, M., 2006. Daime, a Novel Image Analysis Program for Microbial Ecology and Biofilm Research. Environ. Microbiol. 8, 200-213. https://doi.org/10.1111/j.14622920.2005.00880.x

Ekama, G.A., Wentzel, M.C., 2008. Organic matter removal. In: Biological wastewater treatment: principles, modelling and design, Henze, M., van Loosdrecht, M.C.M., Ekama, G.A. and Brdjanovic, D. (Eds.), ISBN: 9781843391883 . IWA Publishing, London, UK.

Grady, C.P.L.J., Daigger, G.T., Lim, H.C., 1999. Biological Wastewater Treatment, 2nd ed. Marcel Dekker, Inc., New York, NY.

Gu, A.Z., Saunders, A., Neethling, J.B., Stensel, H.D., Blackall, L.L., 2008. Functionally relevant microorganisms to enhanced biological phosphorus removal performance at full-scale wastewater treatment plants in the United States. Water Environ. Res. 80, 688-698. https://doi.org/10.2175/106143008X276741

Guerrero, J., Guisasola, A., Baeza, J.A., 2011. The nature of the carbon source rules the competition between PAO and denitrifiers in systems for simultaneous biological nitrogen and phosphorus removal. Water Research, 45(16), 4793-4802.

Hao, X., Wang, Q., Cao, Y., Van Loosdrecht, M.C.M., 2010. Experimental evaluation of decrease in the activities of polyphosphate/glycogen-accumulating organisms due to cell death and activity decay in activated sludge. Biotechnol. Bioeng. 106, 399-407. https://doi.org/10.1002/bit.22703

He, S., Gu, A.Z., McMahon, K.D., 2008. Progress toward understanding the distribution of Accumulibacter among full-scale enhanced biological phosphorus removal systems. Microb. Ecol. 55, 229-236. https://doi.org/10.1007/s00248-007-9270-x

He, S., McMahon, K.D., 2011. Microbiology of 'Candidatus Accumulibacter'in activated sludge. Microbial biotechnology, 4(5), 603-619.

Henze, M., Harremoes, P., Jansen, J.L.C., Arvin, E., 1997. Wastewater treatment: biological and chemical processes. ISBN 978-3-540-42228-0, Springer, Berlin.

Kong, Y., Nielsen, J.L., Nielsen, P.H., 2005. Identity and Ecophysiology of Uncultured Actinobacterial Polyphosphate-Accumulating Organisms in Full-Scale Enhanced Biological Phosphorus Removal Plants. Appl. Environ. Microbiol. 71, 4076-4085. https://doi.org/10.1128/AEM.71.7.4076

Kozich, J.J., Westcott, S.L., Baxter, N.T., Highlander, S.K., Schloss, P.D, 2013. Development of a dual- 
index sequencing strategy and curation pipeline for analyzing amplicon sequence data on the miseq illumina sequencing platform. Appl. Environ. Microbiol. 79: 5112-5120.

Kristiansen, R., Nguyen, H.T.T., Saunders, A.M., Nielsen, J.L., Wimmer, R., Le, V.Q., McIlroy, S.J., Petrovski, S., Seviour, R.J., Calteau, A., Nielsen, K.L., Nielsen, P.H., 2013. A metabolic model for members of the genus Tetrasphaera involved in enhanced biological phosphorus removal. ISME J. 7, 543-54. https://doi.org/10.1038/ismej.2012.136

Kuba, T., Van Loosdrecht, M.C.M., Brandse, F.A., Heijnen, J.J., 1997a. Occurrence of denitrifying phosphorus removing bacteria in modified UCT-type wastewater treatment plants. Water Res. 31, 777-786. https://doi.org/10.1016/S0043-1354(96)00370-3

Kuba, T., Van Loosdrecht, M.C.M., Murnleitner, E., Heijnen, J.J., 1997b. Kinetics and stoichiometry in the biological phosphorus removal process with short cycle times. Water Res. 31, 918-928. https://doi.org/10.1016/S0043-1354(96)00371-5

Lanham, A.B., Oehmen, A., Saunders, A.M., Carvalho, G., Nielsen, P.H., Reis, M.A.M., 2013a. Metabolic versatility in full-scale wastewater treatment plants performing enhanced biological phosphorus removal. Water Res. 47, 7032-7041. https://doi.org/10.1016/j.watres.2013.08.042

Lanham, A.B., Ricardo, A.R., Albuquerque, M.G.E., Pardelha, F., Carvalheira, M., Coma, M., Fradinho, J., Carvalho, G., Oehmen, A., Reis, M.A.M., 2013b. Determination of the extraction kinetics for the quantification of polyhydroxyalkanoate monomers in mixed microbial systems. Process Biochem. 48, 1626-1634. https://doi.org/10.1016/j.procbio.2013.07.023

Lanham, A.B., Ricardo, A.R., Coma, M., Fradinho, J., Carvalheira, M., Oehmen, A., Carvalho, G., Reis, M.A.M., 2012. Optimisation of glycogen quantification in mixed microbial cultures. Bioresour. Technol. 118, 518-525. https://doi.org/10.1016/j.biortech.2012.05.087

López-Vázquez, C.M., Hooijmans, C.M., Brdjanovic, D., Gijzen, H.J., van Loosdrecht, M.C.M., 2008. Factors affecting the microbial populations at full-scale enhanced biological phosphorus removal (EBPR) wastewater treatment plants in The Netherlands. Water Res. 42, 2349-2360. https://doi.org/10.1016/j.watres.2008.01.001

López-Vázquez, C.M., Hooijmans, C.M., Brdjanovic, D., Gijzen, H.J., van Loosdrecht, M.C.M., 2008. Factors affecting the microbial populations at full-scale enhanced biological phosphorus removal (EBPR) wastewater treatment plants in The Netherlands. Water Res. 42, 2349-2360. https://doi.org/10.1016/j.watres.2008.01.001

López-Vázquez, C.M., Oehmen, A., Hooijmans, C.M., Brdjanovic, D., Gijzen, H.J., Yuan, Z., van Loosdrecht, M.C.M., 2009. Modeling the PAO-GAO competition: Effects of carbon source, $\mathrm{pH}$ and temperature. Water Res. 43, 450-462. https://doi.org/10.1016/j.watres.2008.10.032

Lu, H., Keller, J., Yuan, Z., 2007. Endogenous metabolism of Candidatus Accumulibacter phosphatis under various starvation conditions. Water Res. 41, 4646-4656. https://doi.org/10.1016/j.watres.2007.06.046

Lu, H., Oehmen, A., Virdis, B., Keller, J., Yuan, Z., 2006. Obtaining highly enriched cultures of Candidatus Accumulibacter phosphates through alternating carbon sources. Water Res. 40, 38383848. https://doi.org/10.1016/j.watres.2006.09.004

Marques, R., Santos, J., Nguyen, H., Carvalho, G., Noronha, J.P., Nielsen, P.H., Reis, M.A.M., Oehmen, A., 2017. Metabolism and ecological niche of Tetrasphaera and Ca. Accumulibacter in enhanced biological phosphorus removal. Water Res. https://doi.org/10.1016/j.watres.2017.04.072

McIlroy, S.J., Albertsen, M., Andresen, E.K., Saunders, A.M., Kristiansen, R., Stokholm-Bjerregaard, M., Nielsen, K.L., Nielsen, P.H., 2014. 'Candidatus Competibacter'-lineage genomes retrieved from metagenomes reveal functional metabolic diversity. The ISME journal, 8(3), 613.

Mielczarek, A.T., Nguyen, H.T.T., Nielsen, J.L., Nielsen, P.H.H., 2013. Population dynamics of bacteria involved in enhanced biological phosphorus removal in Danish wastewater treatment plants. Water Res. 47, 1529-1544. https://doi.org/10.1016/j.watres.2012.12.003

Mino, T., Van Loosdrecht, M.C.M., Heijnen, J.J., 1998. Microbiology and biochemistry of the enhanced biological phosphate removal process. Water Res. 32, 3193-3207. https://doi.org/10.1016/S00431354(98)00129-8

Neethling, J.B., Bakke, B., Benisch, M., Gu, A., Stephens, H., Stensel, H.D., Moore, R., 2005. Factors Influencing the Reliability of Enhanced Biological Phosphorus Removal.

Nguyen, H.T.T., Kristiansen, R., Vestergaard, M., Wimmer, R., Nielsen, P.H., 2015. Intracellular Accumulation of Glycine in Polyphosphate-Accumulating Organisms in Activated Sludge, a Novel Storage Mechanism under Dynamic Anaerobic-Aerobic Conditions. Appl. Environ. Microbiol. 81, 
4809-18. https://doi.org/10.1128/AEM.01012-15

Nguyen, H.T.T., Le, V.Q., Hansen, A.A., Nielsen, J.L., Nielsen, P.H., 2011. High diversity and abundance of putative polyphosphate-accumulating Tetrasphaera-related bacteria in activated sludge systems. FEMS Microbiol. Ecol. 76, 256-267. https://doi.org/10.1111/j.1574-6941.2011.01049.x

Nielsen, P.H., Vollertsen, J., Sorensen, K.H., 2014. Method and a system for out-competing glycogenaccumulating organisms in a substance. US 2014/0319053 A1.

Oehmen, A., Lemos, P.C., Carvalho, G., Yuan, Z., Keller, J., Blackall, L.L., Reis, M. a M., 2007. Advances in enhanced biological phosphorus removal: From micro to macro scale. Water Res. 41, 2271-2300.

Oehmen, A., Saunders, A.M., Vives, M.T., Yuan, Z., Keller, J., 2006. Competition between polyphosphate and glycogen accumulating organisms in enhanced biological phosphorus removal systems with acetate and propionate as carbon sources. J. Biotechnol. 123, 22-32. https://doi.org/10.1016/j.jbiotec.2005.10.009

Oehmen, A., Yuan, Z., Blackall, L.L., Keller, J., 2005. Comparison of acetate and propionate uptake by polyphosphate accumulating organisms and glycogen accumulating organisms. Biotechnol. Bioeng. 91, 162-168. https://doi.org/10.1002/bit.20500

Onnis-Hayden, A., Majed, N., Schramm, A., Gu, A.Z., 2011. Process optimization by decoupled control of key microbial populations: Distribution of activity and abundance of polyphosphate-accumulating organisms and nitrifying populations in a full-scale IFAS-EBPR plant. Water research, 45(13), 38453854.

Petersen, G., 2002. Biologisk Slamhydrolyse af aktivt slam (Biological Sludge Hydrolysis of activated sludge). Spildevandsteknisk Tidsskr. 4, 2-6.

Randall, C.W., Barnard, J.L., Stensel, H.D., 1998. Design and Retrofit of Wastewater Treatment Plants for Biological Nutrient Removal. CRC Press.

Rittmann, B. E., Mayer, B., Westerhoff, P., Edwards, M., 2011. Capturing the lost phosphorus. Chemosphere, 84(6), 846-853.

Rodrigo, M.A., Seco, A., Ferrer, J., Penya-Roja, J.M., 1999. The Effect of Sludge Age on the Deterioration of the Enhanced Biological Phosphorus Removal Process. Environ. Technol. 20, 1055-1063. https://doi.org/10.1080/09593332008616902

Shen, N., Zhou, Y., 2016. Enhanced biological phosphorus removal with different carbon sources. Appl. Microbiol. Biotechnol. 100, 4735-4745. https://doi.org/10.1007/s00253-016-7518-4

Smolders, G.J.F., 1995. A structured metabolic model for the anaerobic and aerobic stoichiometry of the biological phosphorus removal process. Biotechnology and Bioengineering. Biotechnol. Bioeng. 47, 277-287.

Smolders, G.J.F., van der Meij, J., van Loosdrecht, M.C.M., Heijnen, J.J., 1994a. Model of the Anaerobic Metabolism of the Biological Phosphorus Removal Process: Stoichiometry and pH Influence. Biotechnol. Bioeng. 43, 461-470. https://doi.org/10.1002/bit.260440709

Smolders, G.J.F.J., van der Meij, J., Van Loosdrecht, M.C.M., Heijnen, J.J., 1994b. Stoichiometric Model of the Aerobic Metabolism of the Biological Phosphorus Removal Process. Biotechnol. Bioeng. 44, 837-848. https://doi.org/10.1002/bit.260440709

Stokholm-Bjerregaard, M., Drouet, K., Humbert, H., Borregaard, V.R., Lemaire, R., Vollertsen, J., Nielsen, P.H., 2015. Return Sludge Side-stream - How to Control GAOs and Ensure Successful EBPR in Hot Climates, in: 12th IWA Specialized Conference on Design, Operation, and Economics of Large Wastewater Treatment Plants. Prague, Czech Republic.

Stokholm-Bjerregaard, M., McIlroy, S.J., Nierychlo, M., Karst, S.M., Albertsen, M., Nielsen, P.H., 2017. A critical assessment of the microorganisms proposed to be important to enhanced biological phosphorus removal in full-scale wastewater treatment systems. Front. Microbiol. 8, 718. https://doi.org/10.3389/FMICB.2017.00718

Tetreault, M.J., Benedict, A.H., Kaempfer, C., Barth, E.F., 1986. Biological Phosphorus Removal: A Technology Evaluation. J. (Water Pollut. Control Fed. 58, 823-837.

Tooker, N. B.; Guangu, L.; Bott, C. B.; Dombrowski, P.; Schauer, P.; Menniti, A.; Shaw, A.; Barnard, J. L.; Stinson, B.; Stevens, G.; Dunlap, P.; Takacs, I.; Phillips, H.; Analla, H.; Russell, A.; Ellsworth, A.; McQuarrie, J.; Carson, K.; Onnis-Hayden, A.; Gu, A. Z., 2017. Rethinking and Reforming EBPR Strategy - Concepts and Mechanisms of Side-Stream EBPR. Proceedings of the 90th Annual Water Environment Federation Technical Exhibition and Conference. Chicago, Illinois, Sept 30-Oct 4, 2017; Water Environment Federation: Alexandria, Virginia; pp 2547-2564.

Tu, Y., Schuler, A.J., 2013. Low acetate concentrations favor polyphosphate-accumulating organisms over 
glycogen-accumulating organisms in enhanced biological phosphorus removal from wastewater. Environ. Sci. Technol. 47, 3816-3824. https://doi.org/10.1021/es304846s

Ucisik, A.S., Henze, M., 2008. Biological hydrolysis and acidification of sludge under anaerobic conditions: The effect of sludge type and origin on the production and composition of volatile fatty acids. Water Res. 42, 3729-3738. https://doi.org/10.1016/j.watres.2008.06.010

Vollertsen, J., Petersen, G., Borregaard, V.R., 2006. Hydrolysis and fermentation of activated sludge to enhance biological phosphorus removal. Water Sci. Technol. 53, 55-64.

Wentzel, M., Dold, P., Ekama, G., Marais, G., 1989. Enhanced polyphosphate organism cultures in activated sludge systems: Part 2 Experimental Behaviour. Water SA 15, 71-88.

Whang, L.-M., Park, J.K., 2006. Competition between Polyphosphate- and Glycogen-Accumulating Organisms in Enhanced-Biological-Phosphorus-Removal Systems: Effect of Temperature and Sludge Age. Water Environ. Res. 78, 4-11. https://doi.org/10.2175/106143005X84459

Zeng, R.J., van Loosdrecht, M.C.M., Yuan, Z., Keller, J., 2003. Metabolic Model for GlycogenAccumulating Organisms in Anaerobic / Aerobic Activated Sludge Systems. Biotechnol. Bioeng. 81, 93-105. https://doi.org/10.1002/bit.10455

Zilles, J.L., Peccia, J., Kim, M., Hung, C., Noguera, D.R., 2002. Involvement of Rhodocyclus -Related Organisms in Phosphorus Removal in Full-Scale Wastewater Treatment Plants Involvement of Rhodocyclus -Related Organisms in Phosphorus Removal in Full-Scale Wastewater Treatment Plants. Appl. Environ. Microbiol. 68, 2763-2769. https://doi.org/10.1128/AEM.68.6.2763 